\title{
Endogenous modification of the chemoattractant CXCL5 alters receptor usage and enhances its activity toward neutrophils and monocytes
}

Metzemaekers $\mathrm{M}^{1,2,{ }^{*}}$, Mortier $\mathrm{M}^{1,{ }^{*}}$, Vacchini $\mathrm{A}^{2,3}$, Boff $\mathrm{D}^{1,4}$, Yu K ${ }^{1}$, Janssens $\mathrm{R}^{1,4}$, Farina $\mathrm{FM}^{2}$, Milanesi $\mathrm{S}^{2,3}$, Berghmans $\mathrm{N}^{1}$, Pörtner $\mathrm{N}^{1}$, Van Damme $\mathrm{J}^{1}$, Allegretti $\mathrm{M}^{5}$, Teixeira $\mathrm{MM}^{4}$, Locati $\mathrm{M}^{2,3}$, Borroni $\mathrm{EM}^{2,3}$, Almeida Amaral $\mathrm{F}^{4}$ and Proost $\mathrm{P}^{1}$. Endogenous modification of the chemoattractant CXCL5 alters receptor usage and enhances its activity toward neutrophils and monocytes. Sci Signal 2021; 14(673):eaax3053.

${ }^{1}$ Laboratory of Molecular Immunology, Department of Microbiology, Immunology and Transplantation, Rega Institute for Medical Research, KU Leuven, Leuven, Belgium

${ }^{2}$ Humanitas Clinical and Research Center - IRCCS, 20089 Rozzano, Milan, Italy

${ }^{3}$ Department of Medical Biotechnologies and Translational Medicine, University of Milan, Segrate, Italy ${ }^{4}$ Imunofarmacologia, Departamento de Bioquímica e Imunologia, Instituto de Ciências Biológicas, Universidade Federal de Minas Gerais, Belo Horizonte, Minas Gerais, Brasil

${ }^{5}$ Dompé Farmaceutici SpA, L'Aquila, Italy.

*Joint first authors

\begin{abstract}
:
The inflammatory human chemokine CXCL5 interacts with the $\mathrm{G}$ protein-coupled receptor CXCR2 to induce chemotaxis and activation of neutrophils. CXCL5 also has weak agonist activity towards CXCR1. The N-terminus of CXCL5 can be modified by proteolytic cleavage or deimination of $\mathrm{Arg}^{9}$ to citrulline (Cit), and these modifications can occur separately or together. Here, we chemically synthesized native CXCL5(1-78), truncated CXCL5 [CXCL5(9-78)], and the citrullinated ( $\mathrm{Cit}^{9}$ ) versions and characterized their functions in vitro and in vivo. Compared to full-length CXCL5, N-terminal truncation resulted in enhanced potency to induce $G$ protein signaling and $\beta$-arrestin recruitment through CXCR2, increased CXCL5-initiated internalization of CXCR2, and greater $\mathrm{Ca}^{2+}$ signaling downstream of not only CXCR2, but also of CXCR1. Citrullination did not affect the capacity of CXCL5 to activate classical or alternative signaling pathways. Administering the various CXCL5 forms to mice revealed that in addition to neutrophils, CXCL5 exerted chemotactic activity toward monocytes and that this activity was increased by $\mathrm{N}$-terminal truncation. These findings were confirmed by in vitro chemotaxis and $\mathrm{Ca}^{2+}$ signaling assays with primary human $\mathrm{CD}_{14}{ }^{+}$monocytes and human THP-1 monocytes. In vitro and in vivo analyses suggested that CXCL5 targeted monocytes through CXCR1 and CXCR2. Thus, truncation of the $\mathrm{N}$-terminus makes CXCL5 a more potent chemoattractant for both neutrophils and monocytes that acts through CXCR1 as well as CXCR2.
\end{abstract}




\section{Introduction}

Native human CXCL5 is a $8.3 \mathrm{kDa}$ protein belonging to the family of chemotactic cytokines, also called chemokines (1-3). As emphasized by its original name, 'epithelial-derived neutrophil-activating peptide 78' (ENA-78), CXCL5 is best known as an activating and chemotactic factor for neutrophil granulocytes $(4,5)$. The production of CXCL5 by immune cells, such as monocytes, or connective tissue cells, such as epithelial or endothelial cells, depends on prior induction by inflammatory inducers like

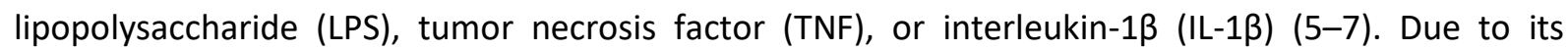
inflammatory nature and proangiogenic potential, CXCL5 has been implicated in inflammation and cancer (8-12). In rheumatoid arthritis for example, synovial tissue fibroblasts and macrophages constitutively produce CXCL5 (13). Notably, CXCL5-targeting antibodies neutralize the neutrophil chemotactic activity present in synovial fluids from these patients by more than $40 \%$, emphasizing the pivotal role for the chemokine in this context (13).

CXCL5 exerts its biological functions primarily through activation of the $\mathrm{G}$ protein-coupled receptor (GPCR) CXCR2, which is most abundant on neutrophils $(12,14)$. In addition, weak CXCR1 agonistic properties have been attributed to CXCL5 (15-17). Human CXCL5 shares its main receptor, CXCR2, with six structurally and functionally related chemokines - namely CXCL1, CXCL2, CXCL3, CXCL6, CXCL7, and CXCL8 - that all contain the tripartite motif Glu-Leu-Arg (ELR) preceding their conserved Cys-Xaa-Cys (CXC) motif $(12,14)$. At first glance, one may therefore have the impression that the CXCR2-chemokine network features a remarkable degree of redundancy. However, it has become clear that each of the CXCR2 ligands is susceptible to specific posttranslational modifications that contribute to functional heterogeneity of these chemokines (18-20). Indeed, the precise modifications that may occur on mature secreted CXCR2 agonists - both the enzymes involved in the modification and the subsequent effects of the modifications - differ between ligands (18).

In the case of $\mathrm{CXCL5}$, limited N-terminal proteolysis barely affects its biological activity, but more extensive $\mathrm{N}$-terminal cleavage by matrix metalloproteinases (MMPs) or cathepsins strongly enhances its neutrophil chemotactic potency (21-26). Full-length $\operatorname{CXCL5(1-78)~dose-dependently~attracts~}$ human neutrophils in vitro but fails to recruit neutrophils to the peritoneal cavity in mice (21). However, the $\mathrm{N}$-terminally truncated forms $\operatorname{CXCL5(8-78)}$ and $\operatorname{CXCL5}(9-78)$ potently attract these leukocytes in a dose-dependent manner in this experimental model. Cells are likely to naturally produce these truncated forms of the chemokine in vivo, because CXCL5(8-78) and CXCL5(9-78) can be isolated from the conditioned medium of primary human monocytes (24). The enzymes responsible for the generation of CXCL5(8-78) are MMP-8 and MMP-9 (20, 22-24), whereas CXCL5(9-78) may be derived from cathepsin- or chymotrypsin-mediated truncation of native CXCL5(1-78) (24-26). Also, the murine structural and functional equivalent of human CXCL5 and CXCL6 is highly susceptible to Nterminal truncation and subsequent activation (27). In contrast to $\mathrm{N}$-terminal cleavage, deimination of the basic arginine residue present at the ninth $\mathrm{N}$-terminal position to a neutral citrulline impairs the inflammatory activity of CXCL5 (21). Furthermore, increased amounts of citrullinated CXCL5 are detected in sera from rheumatoid arthritis patients (28). In direct conflict with the classical dogma that ELR-containing CXC chemokines are selective neutrophil attractants, the authors suggest that this citrullinated form of CXCL5 instead acts as a weak monocyte attractant (28). However, it remains to be elucidated whether the observed monocyte recruitment in this study was directly mediated by CXCL5 itself or rather resulted from CXCL5-induced release of monocyte chemoattractants. 
As indicated above, multiple lines of evidence point to CXCL5 as an important proinflammatory mediator in different types of disease. Moreover, the fact that enzymes known to convert natural CXCL5 into forms with altered biological activities are typically more abundant during inflammation, supporting the hypothesis that posttranslational modifications play an important role in regulating the precise physiological functions of $\mathrm{CXCL5}$ in normal and pathological conditions. Although previous efforts have been made to specify the activity of modified forms of CXCL5, many questions remain. In the present study, we therefore aimed to investigate intensively the effect of posttranslational modifications of CXCL5 on receptor usage, activation of specific downstream signaling pathways, and

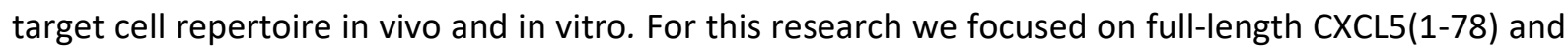
the natural variants $\mathrm{CXCL5}(9-78)$ and $\left[\mathrm{Cit}^{9}\right] \mathrm{CXCL5}(1-78)$. Because we previously showed that citrullination barely effects cathepsin G-mediated potentiation of CXCL5(1-78) to CXCL5(9-78), we also included $\left[\mathrm{Cit}^{9}\right] \mathrm{CXCL5}(9-78)$ in our analysis (21).

\section{Results}

$N$-terminal truncation enhances the potency of CXCL5 for inducing $G$ protein-dependent signaling through CXCR2

Because chemokine receptors belong to the GPCR superfamily, chemokine-induced signaling typically involves $\mathrm{G}$ proteins. Upon activation, most chemokine receptors couple to the inhibitory subtype of $G \alpha$ proteins that mediate the inhibition of adenylate cyclase, thereby reducing endogenous cyclic AMP (CAMP) production. In the first approach to unravel the molecular mechanisms behind the differential activities of CXCL5 forms (21), we compared the capacities of CXCL5(1-78), [Cit ${ }^{9}$ CXCL5(1-78), CXCL5(978), and [Cit $\left.{ }^{9}\right] \mathrm{CXCL5}(9-78)$ to induce a reduction in CAMP through CXCR2. HEK293 cells expressing CXCR2 were treated with the adenylate cyclase activator forskolin to enhance CAMP concentrations and then stimulated with the various forms of CXCL5. Dose-response investigation and IOgEC50 calculations let us conclude that loss of its eight $\mathrm{N}$-terminal amino acids significantly augmented the capacity of CXCL5 to stimulate CXCR2-mediated, G protein-dependent signaling (Fig. 1A). Citrullination rather weakened the potency of CXCL5 in this signaling assay, but no significant differences were detected.

\section{$N$-terminal truncation promotes CXCL5-induced CXCR2 internalization and B-arrestin recruitment}

As an alternative to $\mathrm{G}$ protein-mediated signaling, ligand-induced activation of chemokine receptors may lead to the initiation of $\beta$-arrestin-dependent intracellular signaling. We used bioluminescence resonance energy transfer (BRET) technology to monitor the recruitment of $\beta$-arrestins 1 and 2 to transgenically expressed CXCR2 in HEK293 cells that were stimulated with CXCL5(1-78), [Cit ${ }^{9}$ CXCL5(178), $\mathrm{CXCL5}$ (9-78), or [Cit $\left.{ }^{9}\right] \mathrm{CXCL5}$ (9-78). Kinetic measurements were performed and showed clear recruitment of both $\beta$-arrestins to CXCR2 if cells were exposed to the $\mathrm{N}$-terminally truncated forms CXCL5(9-78) and [Cit $\left.{ }^{9}\right] \operatorname{CXCL5}$ (9-78) (Fig. 1B). No $\beta$-arrestin recruitment was detected if an equal dose of CXCL5(1-78) or [Cit $\left.{ }^{9}\right]$ CXCL5(1-78) was administered. Because of $\beta$-arrestin recruitment also induces GPCR internalization, we tested the ability of CXCL5 forms to induce internalization of endogenous CXCR2 on human neutrophils using a flow cytometry-based approach. Compared to stimulation with buffer, CXCL5(9-78) and [Cit ${ }^{9}$ CXCL5(9-78) strongly provoked CXCR2 internalization at concentrations of $30 \mathrm{nM}$ and greater, whereas the minimal effective concentration of CXCL5(1-78) or [Cit ${ }^{9}$ CXCL5(1- 
78) was at least three times higher (Fig. 1C). Dose-response analysis showed that CXCL5(9-78) and $\left[\mathrm{Cit}^{9}{ }^{9} \mathrm{CXCL5}\right.$ (9-78) were significantly more potent than $\mathrm{CXCL5}(1-78)$ at most test concentrations (Fig. 1C). No significant differences were found between citrullinated CXCL5 forms and their noncitrullinated homologues.
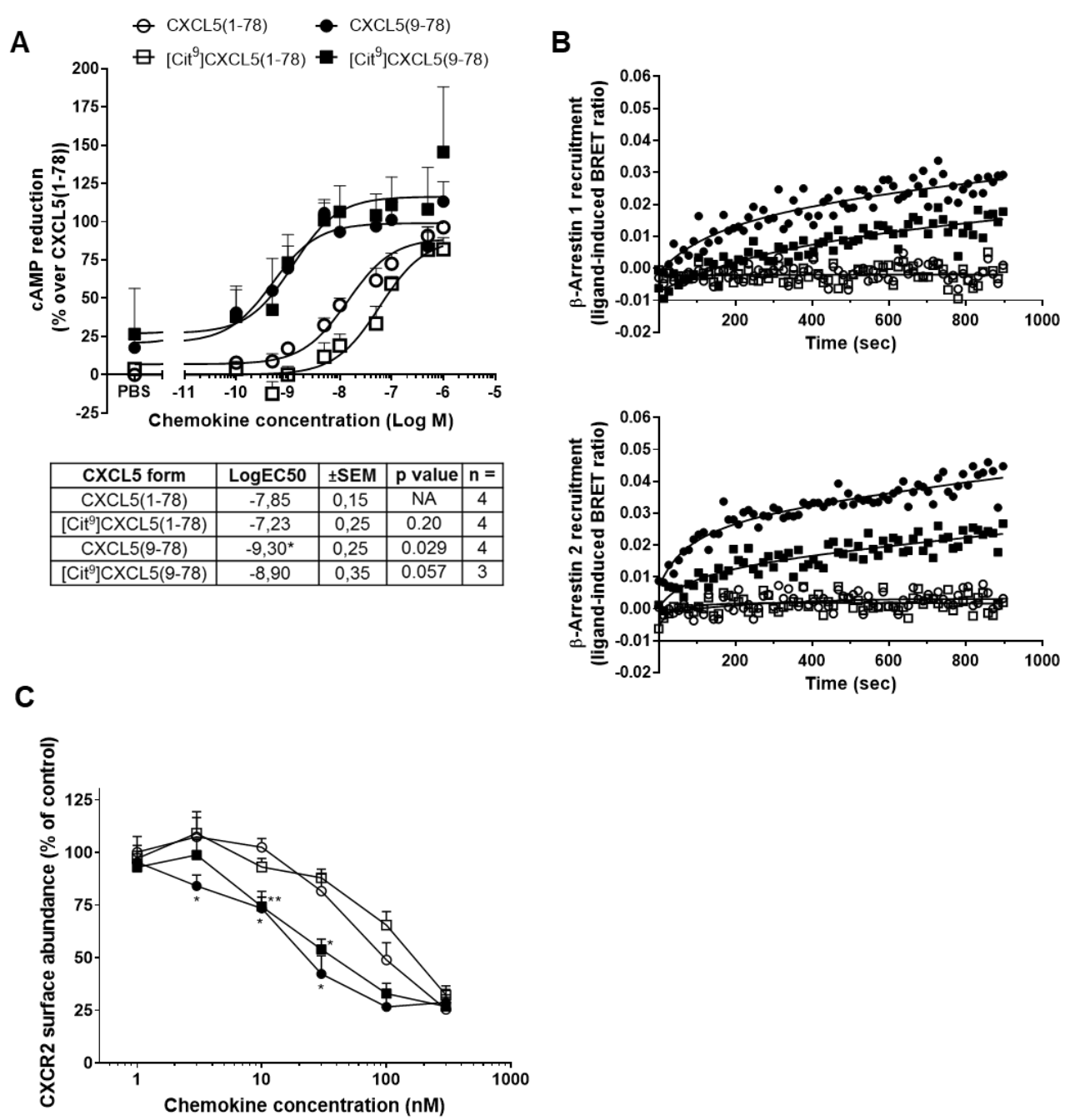

Fig. 1. Effect of N-terminal processing on CXCL5-induced CXCR2 signaling and internalization. CXCL5(1-78), [Cit $\left.{ }^{9}\right] \mathrm{CXCL5}$ (1-78), $\mathrm{CXCL5}$ (9-78), and [ $\left.\mathrm{Cit}^{9}\right] \mathrm{CXCL5}$ (9-78) were compared in signaling and internalization assays. (A) HEK293T cells transfected with a construct encoding CXCR2 were stimulated with the forms of CXCL5 as indicated in the presence of Forskolin, and the reduction in CAMP was measured. Dose-response measurements and EC50 calculations were performed based on Alphascreen technology. $n \geq 3$ independent experiments. Mean LogEC50 \pm SEM were obtained by nonlinear regression curve fitting. Results were statistically compared by Mann-Whitney $\mathrm{U}$ tests. ${ }^{*} \mathrm{p}<0.05$, for statistical differences between $\mathrm{CXCL5}$ (1-78) and other CXCL5 forms. (B) Kinetic BRET measurements of $\beta$-arrestin 1 and $\beta$-arrestin 2 recruitment to CXCR2 in CXCR2-expressing HEK293T cells after stimulation with the indicated $\mathrm{CXCL5}$ forms at $100 \mathrm{nM}$ ( $\mathrm{n}=4$ independent experiments). Results are represented as ligand-induced BRET ratio. (C) Flow cytometry was used to determine CXCR2 abundance on freshly purified primary human neutrophils that were stimulated with the indicated concentrations of CXCL5 molecules for $1 \mathrm{~h}$. Results are represented as relative receptor abundance (compared to buffer treated cells) \pm SEM after stimulation with the indicated concentrations of CXCL5 forms. $n=6$ independent experiments. Results were statistically compared by Mann-Whitney $U$ tests. ${ }^{*} p<0.05,{ }^{* *} p<0.01$ for statistical differences between CXCL5(1-78) and other CXCL5 forms. 
A

CXCR1
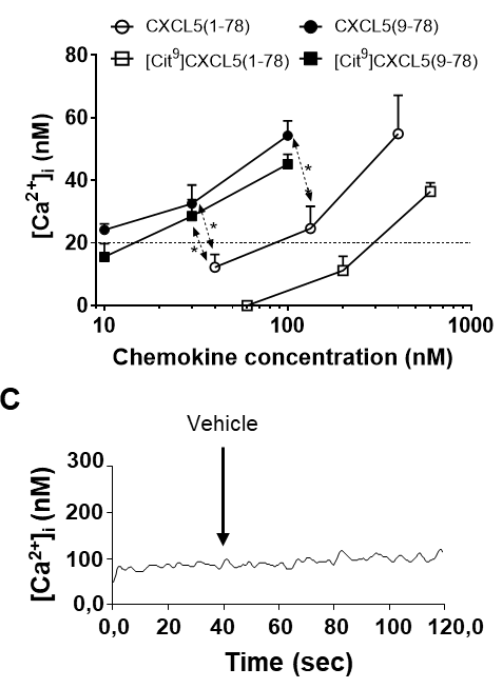

$400 \mathrm{nM}$ CXCL5(1-78)

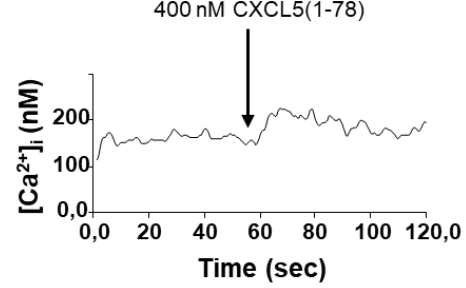

$600 \mathrm{nM}\left[\mathrm{Cit}^{9}\right] \mathrm{CXCL5}(1-78)$

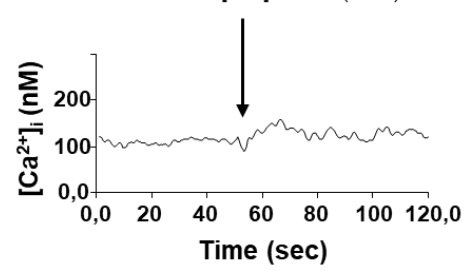

$100 \mathrm{nM}$ CXCL5(9-78)

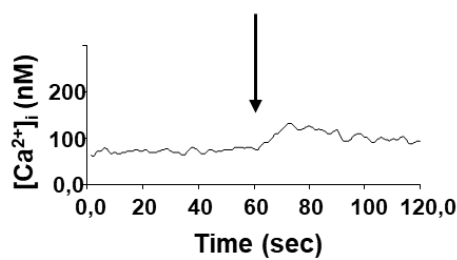

$100 \mathrm{nM}\left[\mathrm{Cit}^{9}\right] \mathrm{CXCL5}(9-78)$

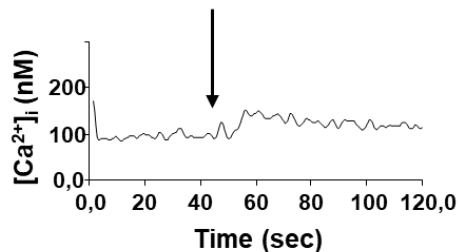

B

CXCR2

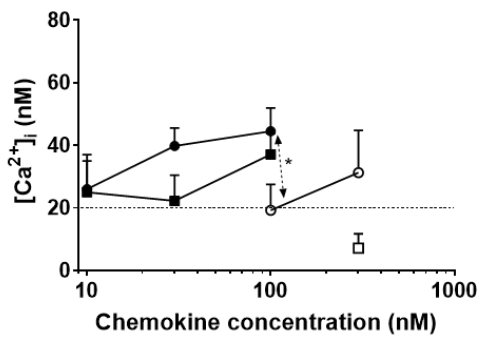

D

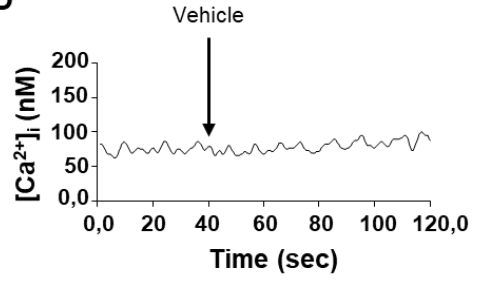

300 nM CXCL5(1-78)

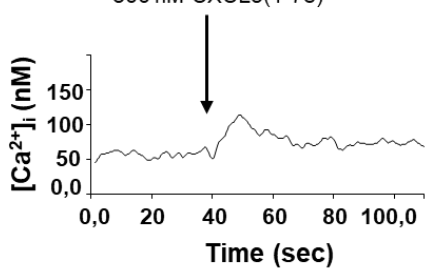

300 nM [Cit $\left.{ }^{9}\right]$ CXCL5 (1-78)

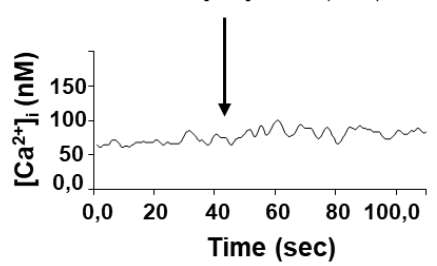

100 nM CXCL5(9-78)

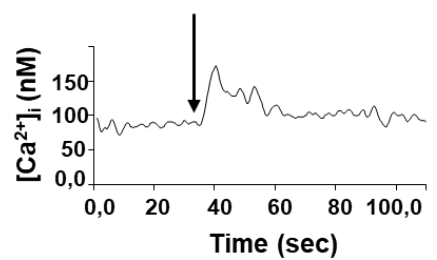

$100 \mathrm{nM}\left[\mathrm{Cit}^{9}\right] \mathrm{CXCL5}(9-78)$

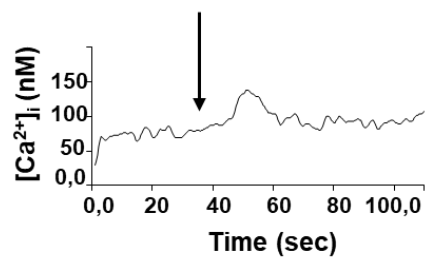

Fig. 2. Effect of $\mathrm{N}$-terminal processing on $\mathrm{CXCL5}$-induced $\mathrm{Ca}^{2+}$ signaling through CXCR1 and CXCR2. HEK cells expressing CXCR1 or CXCR2 were loaded with the $\mathrm{Ca}^{2+}$-binding fluorophore Fura-2 before stimulation with the indicated forms of CXCL5. Intracellular $\mathrm{Ca}^{2+}$ concentrations were calculated using the equation of Grynkiewicz et al (29). (A and B), Dose-response curves of CXCR1-dependent (A) or CXCR2-dependent (B) $\mathrm{Ca}^{2+}$ signaling induced by CXCL5(1-78), [ $\left.\mathrm{Cit}^{9}\right] \mathrm{CXCL5}(1-78), \mathrm{CXCL5}$ (9-78), or [ $\left.\mathrm{Cit}^{9}\right] \mathrm{CXCL5}$ (9-78). Results are presented as mean $\pm \mathrm{SEM}$ and were statistically compared by Mann-Whitney tests. $n \geq 4$ independent experiments. $* p<0.05$ for statistical differences between $\mathrm{CXCL5}$ (1-78) and other CXCL5 forms. The dashed line indicates the detection limit (20 nM). (C and D) Representative experiments showing the $\mathrm{Ca}^{2+}$ response in CXCR1 (C) or CXCR2 (D) transfectants stimulated with the indicated CXCL5 forms or vehicle. 
Native CXCL5(1-78) is a classical CXCR2 ligand that exhibits only weak CXCR1 agonistic properties (1517). However, because N-terminal truncation potentiates the activity of CXCL5 on CXCR2, we speculated that posttranslational modifications of CXCL5 may also affect CXCL5-CXCR1 interactions. To investigate this hypothesis, we evaluated the potency of CXCL5(1-78), [Cit $\left.{ }^{9}\right] \operatorname{CXCL5}(1-78), \mathrm{CXCL5}$ (9-78), and $\left[\mathrm{Cit}^{9}\right] \mathrm{CXCL5}$ (9-78) to induce $\mathrm{Ca}^{2+}$ signaling through transgenically expressed CXCR1 and CXCR2 in HEK293 cells. $\mathrm{N}$-terminal truncation strongly enhanced the potency of CXCL5 to induce $\mathrm{Ca}^{2+}$ signaling through both receptors (Fig 2, A to D). Although citrullination tended to decrease the potency of CXCL5 to induce CXCR1-mediated $\mathrm{Ca}^{2+}$ signaling, no significant differences were found when [ $\left.\mathrm{Cit}^{9}\right] \mathrm{CXCL5}(1-$ 78) and $\left[\mathrm{Cit}^{9}\right] \mathrm{CXCL5}(9-78)$ were statistically compared with their non-citrullinated equivalents (Fig. 2, A to $D)$.

\section{CXCL5 induces recruitment of monocytes in vivo in a manner that depends on CXCR1 or CXCR2}

We previously compared the in vivo chemotactic activity of intraperitoneally (i.p.) injected CXCL5 and found that its potency to recruit neutrophils is strongly increased by N-terminal truncation (21). Given the reported abundance of CXCL5 in the synovial fluids of patients with rheumatoid arthritis (8), we

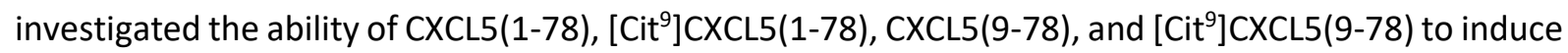
leukocyte recruitment into the tibiofemoral joint of mice by intra articular (i.a.) injection of the chemokines. Compared to the i.p. model, this i.a. model has the advantage of very low basal leukocyte counts, and therefore allowed us to thoroughly investigate the target cell repertoire of CXCL5 forms in vivo. Initially, $\mathrm{CXCL5}(1-78), \operatorname{CXCL5}(9-78)$, and $\left[\mathrm{Cit}^{9}\right] \mathrm{CXCL5}(9-78)$ were injected into the tibiofemoral articulation. Compared to vehicle, all three CXCL5 forms provoked a significant recruitment of neutrophils into the joint (Fig. 3A). In line with our previous results with the i.p. model, truncation strongly enhanced the neutrophil chemotactic activity of CXCL5, whereas the opposite was true for citrullination. In contrast to our expectations, i.a. injection of CXCL5 forms was also associated with remarkably high monocyte recruitment (Fig. 3A).

In view of these unexpected results, these experiments were repeated with CXCL5(1-78), $\left[\mathrm{Cit}^{9}\right] \mathrm{CXCL5}(1-78), \mathrm{CXCL5}(9-78)$, and $\left[\mathrm{Cit}^{9}\right] \operatorname{CXCL5}(9-78)$ in a different laboratory (Fig. 3B). Although the absolute cell numbers were different (probably due to differences in animal source and housing), a significant monocyte extravasation into the joint was provoked by all CXCL5 forms. Compared to native (full-length and non-citrullinated) CXCL5(1-78), the truncated forms CXCL5(9-78) and [Cit ${ }^{9}$ ]CXCL5(9-78) displayed a significantly increased potency to recruit monocytes. No significant differences were found between citrullinated CXCL5 forms and the non-citrullinated equivalents. Due to higher background amounts of neutrophils in the synovial fluids in these additional experiments, the effect of the various CXCL5 forms on neutrophil recruitment was difficult to assess. However, results generated independently in two different laboratories with mice derived from different vendors and kept in different animal houses demonstrate the capacity of CXCL5 to recruit monocytes, in addition to neutrophils, after i.a. injection in vivo. Furthermore, analysis of murine synovial fluids revealed no increased amounts of the prototypical monocyte attractants CCL2 or CCL3 after i.a. injection of the various forms of CXCL5 (Fig. S1, A and B), suggesting that CXCL5 exerted a direct chemotactic effect on monocytes. The absence of CCL2 and CCL3 in supernatant from human endothelial cells (Fig. S1, C and 
D) and peripheral blood mononuclear cells (PBMCS) (Fig. S1, E and F) after stimulation with CXCL5(178), [Cit $\left.{ }^{9}\right] \operatorname{CXCL5}(1-78), \operatorname{CXCL5}(9-78)$, or [Cit $\left.{ }^{9}\right] \operatorname{CXCL5}(9-78)$ supported this hypothesis.

A
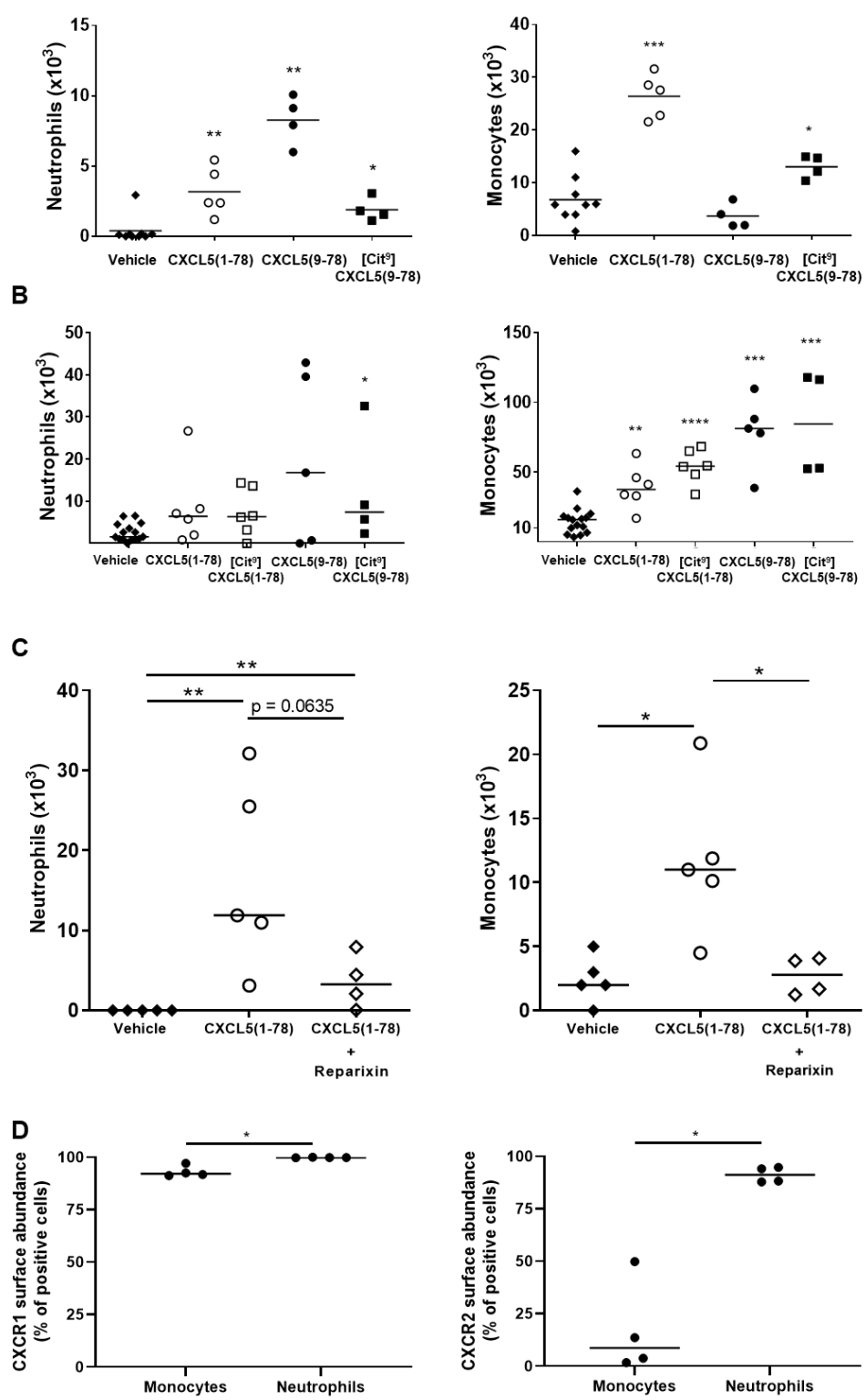

Fig. 3. In vivo target cell repertoire of native and modified CXCL5. (A and B) CXCL5(1-78), CXCL5(9-78), $\left[\mathrm{Cit}^{9}\right] \mathrm{CXCL5}$ (9-78), or vehicle was injected into the tibiofemoral articulation of C57BL/6 mice. Total numbers of leukocytes that migrated into the joint were determined $3 \mathrm{~h}$ after injection, followed by differential cell counting by cytospin to determine the relative abundances of neutrophils and monocytes. Experiments were performed independently in laboratories in Brazil (A) and Belgium (B) using different amounts of each ligand (see Materials and Methods). Each symbol represents an individual mouse, $n \geq 4$ mice per group. Horizontal lines indicate the median number of cells for each treatment group. Results were statistically compared by Mann-Whitney $U$ tests. $* \mathrm{p}<0.05, * * \mathrm{p}<0.01, * * * \mathrm{p}<0.001, * * * * \mathrm{p} \leq 0.0001$, compared to vehicle. (C) CXCL5(1-78) or vehicle was injected into the tibiofemoral articulation of untreated or reparixin-treated C57BL/6 mice. Total leukocyte numbers and relative abundances of neutrophils and monocytes migrated into the joint were determined $3 \mathrm{~h}$ after injection as in ( $A$ and $B$ ). Each symbol represents an individual mouse, $n \geq 4$ mice per group). Horizontal lines indicate the median number of cells for each treatment group. Results were statistically compared by MannWhitney $U$ tests. ${ }^{*} p<0.05, * * p<0.01$. (D) Abundances of CXCR1 and CXCR2 on murine blood monocytes and neutrophils were determined by flow cytometry. Each symbol represents abundance on leukocytes from an individual mouse, $n=4$ mice. Horizontal lines indicate the median number of positive monocytes and neutrophils. Results were statistically compared by Mann-Whitney $U$ tests. ${ }^{*} p<0.05$. 
To provide more insight into the mechanisms underlying CXCL5-mediated monocyte recruitment, the effect of treatment with the CXCR1 and CXCR2 antagonist reparixin was examined. The antagonist was administered prior to i.a. injection of CXCL5(1-78). In line with our initial experiments, CXCL5(1-78) elicited a significant influx of monocytes into the tibiofemoral articulation of control mice (Fig. $3 \mathrm{C}$ ). However, this CXCL5-mediated monocyte recruitment was completely abrogated if the mice were treated systemically with reparixin prior to the i.a. injection. Reparixin pre-treatment also reduced neutrophil extravasation into the joint after i.a. injection with CXCL5(1-78) (Fig. 3C). Using flow cytometry (gating strategy in Fig. S2A-C), we confirmed that the majority of murine blood monocytes were positive for CXCR1 (93.2 $\pm 1.3 \%)$, whereas only a subset were positive for CXCR2 (17.2 $\pm 11.2 \%)$ (Fig. 3D). In contrast, almost all murine blood neutrophils stained positive for both CXCR1 (99.9 \pm $0.04 \%)$ and CXCR2 (91.3 $\pm 1.8 \%$ ) (Fig. 3D).

\section{$N$-terminal truncation increases the chemotactic activity of $\mathrm{CXCL} 5$ for $\mathrm{CD}_{14}^{+}$human monocytes}

We investigated the migratory response of human CD14+ monocytes towards of CXCL5(1-78), $\left[\mathrm{Cit}^{9}\right] \mathrm{CXCL5}(1-78), \mathrm{CXCL5}(9-78)$, and $\left[\mathrm{Cit}^{9}\right] \mathrm{CXCL5}(9-78)$ using in vitro Boyden chamber assays. Cells were exposed to different concentrations of the four CXCL5 forms, and chemotactic indices ( $\mathrm{Cl}$ ) were calculated by dividing the number of cells that migrated in response to each chemokine by the number of cells that migrated toward buffer alone. The presence of CXCR1 and CXCR2 on CD14 ${ }^{+}$monocytes was confirmed by flow cytometry (Fig. 4A). Cell preparations were highly pure and did not contain CD16 ${ }^{+}$CD66 b ${ }^{+}$neutrophils (Fig. 4A). In agreement with our in vivo results, all CXCL5 forms mediated monocyte chemotaxis (Fig. 4B). Also the CXCR2-specific ligand CXCL2 and the prototypic dual-tropic human CXCR1 and CXCR2 ligand CXCL8 induced monocyte migration in a dose-dependent manner (Fig. 4, C and D). Due to a weak bell-shaped effect in their dose-response curves, no statistically significant differences were found between $\mathrm{CXCL} 5$ forms, but the minimal effective concentrations were clearly different. Compared to buffer $(\mathrm{Cl}=1)$, the full-length forms $\mathrm{CXCL5}(1-78)$ and $\left[\mathrm{Cit}^{9}\right] \mathrm{CXCL5}(1-78)$ induced a significant monocyte migratory response only at the highest test concentration $(\mathrm{Cl}=5.2$ for $\mathrm{CXCL5}$ (178) and $\mathrm{Cl}=5.8$ for $\left.\left[\mathrm{Cit}^{9}\right] \mathrm{CXCL5}(1-78)\right)$, whereas the minimal effective concentration of $\mathrm{CXCL5}(9-78)$ and $\left[\mathrm{Cit}^{9}\right] \mathrm{CXCL5}(9-78)$ was at least tenfold lower. 
A

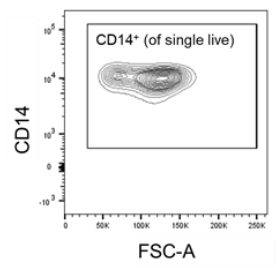

B

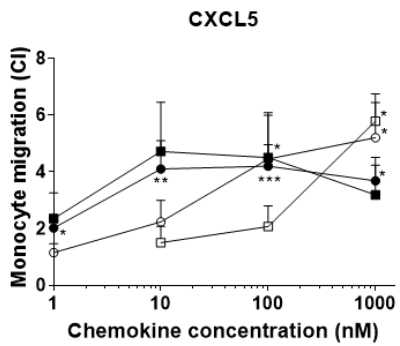

C

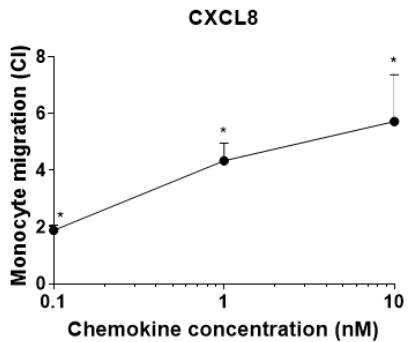

D

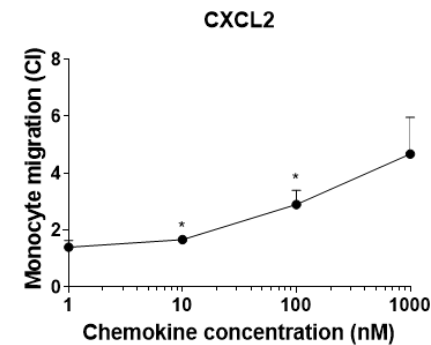

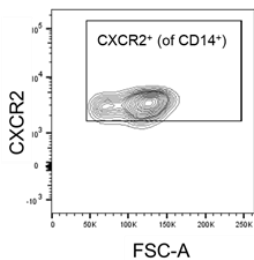

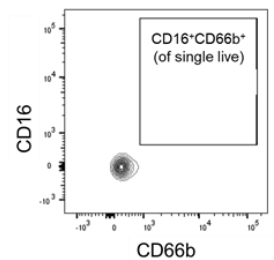

E

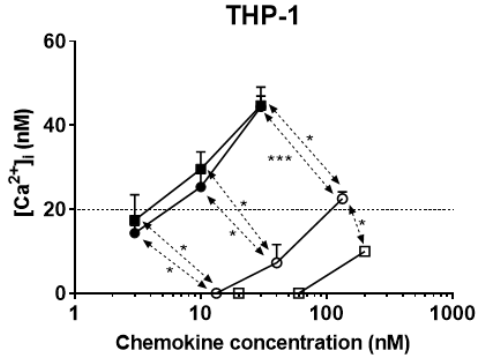

F

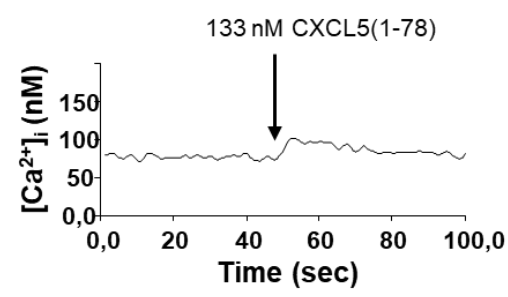

$200 \mathrm{nM}\left[\mathrm{Cit}^{9}\right] \mathrm{CXCL5}(1-78)$

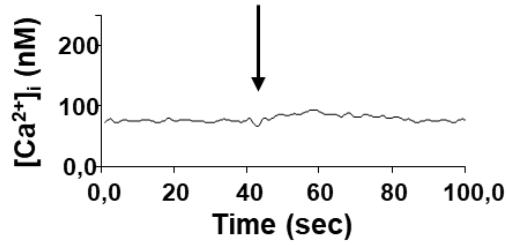

$30 \mathrm{nM}$ CXCL5(9-78)
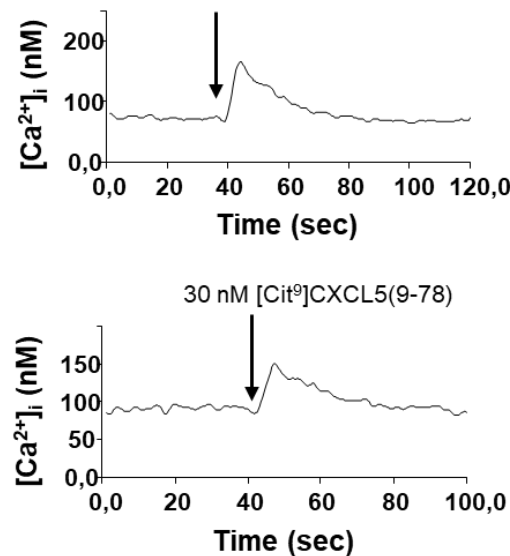

Fig. 4. Differential potencies of CXCL5 forms to induce monocyte chemotaxis and $\mathrm{Ca}^{2+}$ signaling in vitro. (A) The purity of isolated human $\mathrm{CD}_{1} 4^{+}$monocytes and the presence of CXCR1 and CXCR2 on the cell surface was confirmed by flow cytometry. The abundance of $\mathrm{CD} 16^{+} \mathrm{CD} 66 \mathrm{~b}^{+}$cells was determined to assess neutrophil contamination. Results are representative of $n=4$ independent experiments. (B to $\mathbf{D})$ The migratory responses of $\mathrm{CD}_{14}{ }^{+}$human monocytes towards the indicated concentrations of $\mathrm{CXCL5}$ (1-78) [open circles], [Cit ${ }^{9}$ ]CXCL5(178) [open squares], CXCL5(9-78) [filled circles], and [Cit ${ }^{9}$ CXCL5(9-78) [filled squares] (B), CXCL8 (C), or CXCL2 (D) 
were determined in vitro using the Boyden chamber chemotaxis assay. Chemotactic indices $(\mathrm{Cl})$ were calculated by dividing the number of monocytes that migrated in response to CXCL5 by the number of cells that migrated in response to buffer. Values represent the mean $\mathrm{Cl} \pm$ SEM. $\mathrm{n} \geq 4$ independent experiments. The Wilcoxon signed rank test was performed to statistically compare chemotactic indices relative to buffer control. $* p<0.05, * * p<$ $0.01, * * * \mathrm{p}<0.001$. (E and F) THP-1 cells were loaded with the $\mathrm{Ca}^{2+}$-binding fluorophore Fura-2, then stimulated with CXCL5(1-78) [open circles], [Cit ${ }^{9}$ CXCL5(1-78) [open squares], CXCL5(9-78) [filled circles], or [Cit ${ }^{9}$ CXCL5(978) [filled squares]. Intracellular $\mathrm{Ca}^{2+}$ concentrations were calculated using the equation of Grynkiewicz et al. (29). Dose-response curves (E) and representative examples (F) of $\mathrm{Ca}^{2+}$ signaling induced by each form of CXCL5 (E) are shown. Results are represented as mean \pm SEM and were statistically compared by Mann-Whitney $U$ tests. $n$ $\geq 4$ independent experiments. ${ }^{*} p<0.05,{ }^{* *} p<0.01, * * * p<0.001$, for statistical differences between CXCL5(178) and other CXCL5 forms. The dashed line indicates the detection limit ( $20 \mathrm{nM})$.

$\mathrm{N}$-terminal truncation potentiates the capacity of CXCL5 to induce $\mathrm{Ca}^{2+}$ signaling in THP-1 monocytes through CXCR1 and CXCR2

We performed $\mathrm{Ca}^{2+}$ mobilization assays as an alternative approach to assess the in vitro effects of CXCL5 on THP-1 cells, a line of human monocytic cells, and the consequences of posttranslational modifications in this context. The vast majority of monocytic THP-1 cells used in these experiments were positive for CXCR1 $(92.0 \pm 2.1 \%$; $n=6)$ whereas the percentage of CXCR2-positive cells was remarkably lower $(43.0 \pm 12.7 \% ; n=6)$. Cells were loaded with the fluorescent $\mathrm{Ca}^{2+}$ indicator Fura- 2 , and $\mathrm{Ca}^{2+}$ responses were calculated after stimulation with $\mathrm{CXCL5}$ (1-78), [Cit $\left.{ }^{9}\right] \operatorname{CXCL5}(1-78), \mathrm{CXCL5}$ (9-78), or [Cit $\left.{ }^{9}\right] \mathrm{CXCL5}(9-78)$ using the Grynkiewicz equation (Fig. 4, E and F). In terms of minimal effective concentration, $\mathrm{CXCL5}(9-78)$ and $\left[\mathrm{Cit}^{9}\right] \mathrm{CXCL} 5(9-78)$ induced a significant $\mathrm{Ca}^{2+}$ response from $3 \mathrm{nM}$ onwards, whereas at least 30 times higher concentrations of full-length CXCL5 forms were required. Dose-response curves clearly showed the significantly enhanced potency of CXCL5(9-78) and $\left[\mathrm{Cit}^{9}\right] \mathrm{CXCL5}(9-78)$ in comparison with $\mathrm{CXCL5}(1-78)$ (Fig. 4E). Desensitization experiments were performed to address the which receptor(s) were required for $\mathrm{CXCL5}$-initiated $\mathrm{Ca}^{2+}$ signaling in these cells (24). As expected, pre-stimulation with the major monocyte attractant CCL2 did not hinder the $\mathrm{Ca}^{2+}$ response induced by $\mathrm{CXCL5}(9-78)$ and vice versa, implying that CXCL5 exerted its signaling effects independently of CCR2 (Fig. 5, A and B). However, the ability of CXCL5(9-78) to induce $\mathrm{Ca}^{2+}$ mobilization in THP-1 cells was strongly diminished if cells had already been exposed to CXCL8 or CXCL2 (Fig. 5, C to F). CXCL5(9-78) also potently desensitized CXCL8- and CXCL2-mediated signaling. In summary, these results demonstrate the potency of CXCL5 and other CXCR1 and CXCR2 ligands to induce $\mathrm{Ca}^{2+}$ signaling in monocytic cells through CXCR2-and likely also CXCR1-with $\mathrm{N}$-terminal truncation promoting these activities. 

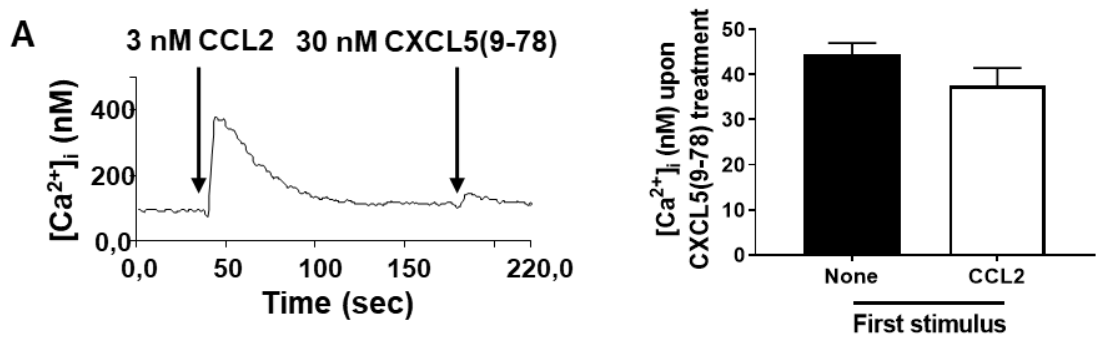

B
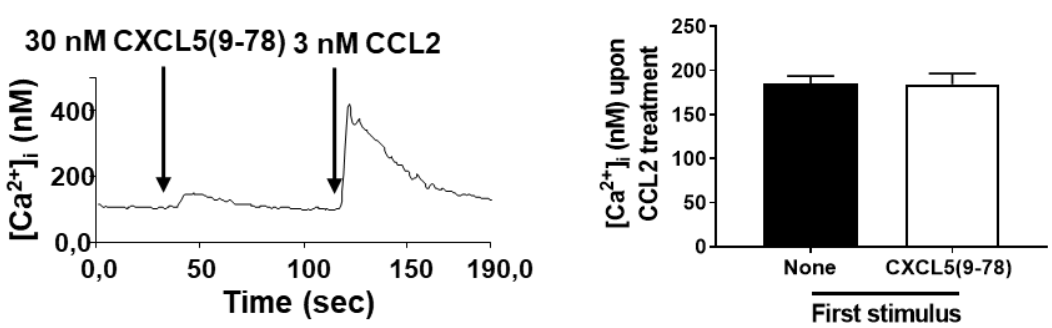

C
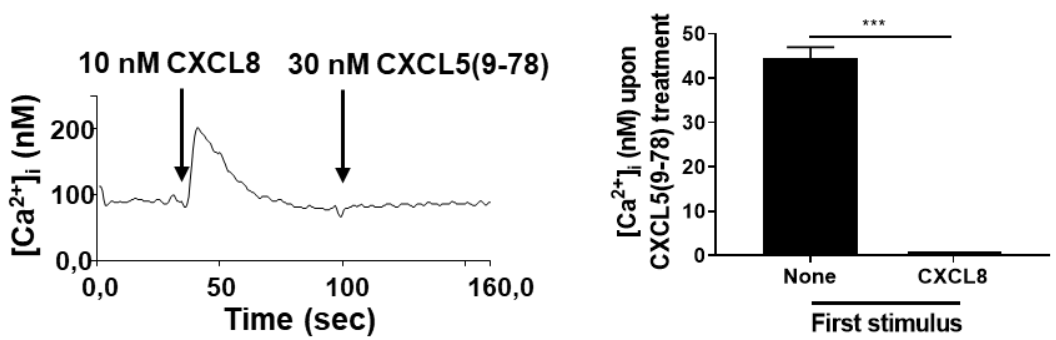

D
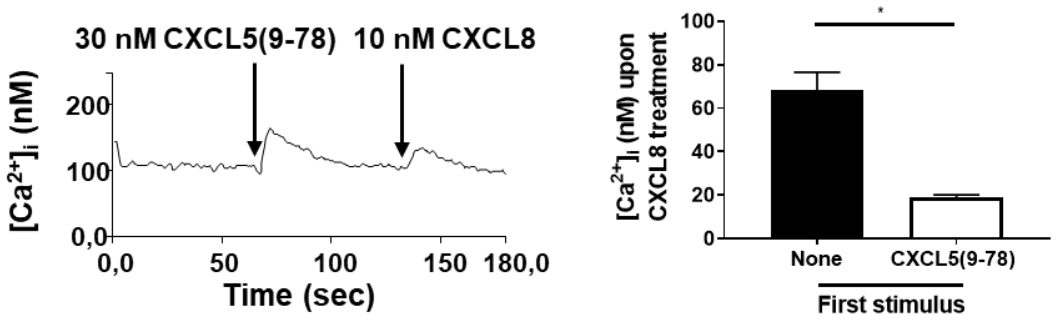

$\mathbf{E}$
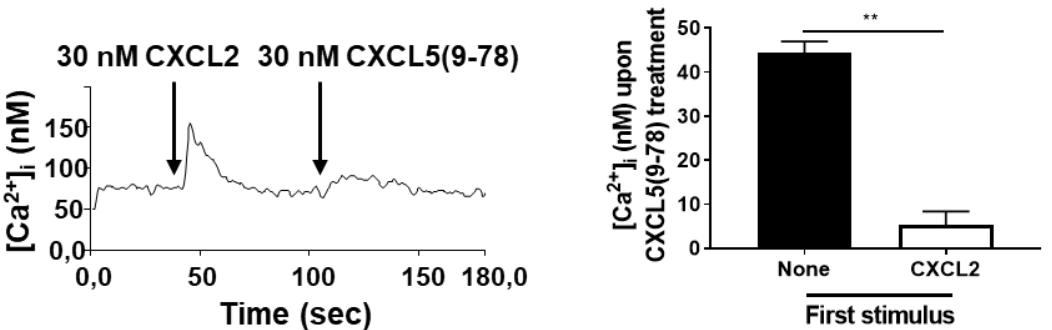

F
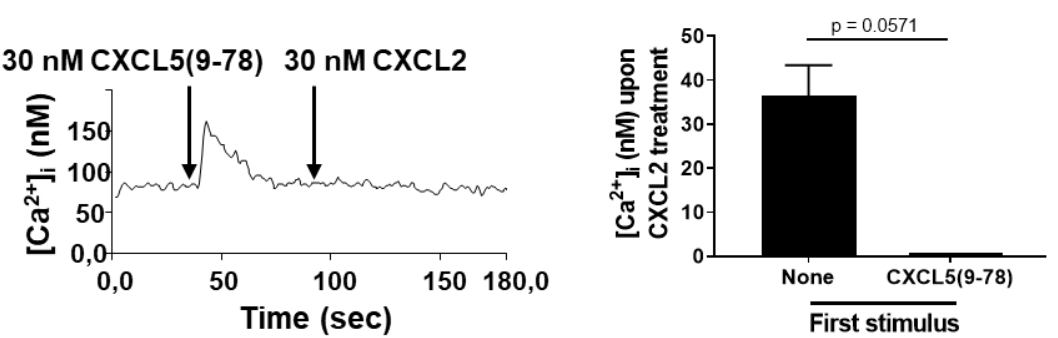

Fig. 5. Desensitization of CXCL5-dependent $\mathrm{Ca}^{2+}$ signaling in THP-1 cells by CXCL2 and CXCL8. THP-1 cells, loaded with the $\mathrm{Ca}^{2+}$-binding fluorophore Fura-2, were treated with CCL2 (A and B), CXCL8 (C and D) or CXCL2 (E and F) prior to or after stimulation with CXCL5(9-78). Representative experiments are depicted by traces, and bar graphs show the $\mathrm{Ca}^{2+}$ fluxes induced by the second stimulation. $\mathrm{n} \geq 4$ independent experiments. Results were statistically compared by Mann-Whitney tests. ${ }^{*} \mathrm{p}<0.05$, ${ }^{* *} \mathrm{p}<0.01, * * * \mathrm{p}<0.001$. 


\section{Discussion}

Previous studies demonstrated that $\mathrm{N}$-terminal cleavage potentiates the neutrophil activation and chemotactic properties of CXCL5, whereas citrullination reduces inflammation $(21,24)$. However, the underlying mechanisms have been unraveled only partially. In the present study, we chemically synthesized CXCL5(1-78), [Cit $\left.{ }^{9}\right] \operatorname{CXCL5}(1-78), \mathrm{CXCL}^{2}(9-78)$, and [Cit $\left.{ }^{9}\right] \mathrm{CXCL5}$ (9-78) for extensive biological characterization. Our results demonstrate that loss of the eight most $\mathrm{N}$-terminal amino acids strongly enhanced the capacity of CXCL5 to induce $G$ protein-dependent signal transduction through its cognate receptor CXCR2. G protein-dependent signaling typically results in the release of $\mathrm{Ca}^{2+}$ from the endoplasmic reticulum and the subsequent activation of $\mathrm{Ca}^{2+}$-dependent cellular responses including increases in integrins, the production of oxygen radicals, phagocytosis, and chemotaxis (30). Thus, the enhanced potency of truncated forms of CXCL5 to induce $G$ protein signaling may at least partially explain why $\mathrm{N}$-terminal truncation strongly enforces the potency of CXCL5 to induce the recruitment of neutrophils (21). Moreover, our results suggest that $\mathrm{N}$-terminal cleavage of CXCL5 expanded its receptor repertoire. Indeed, although native CXCL5(1-78) is generally considered to have only weak or no activity as a CXCR1 agonist, the truncated forms CXCL5(9-78) and [Cit ${ }^{9}$ CXXL5(9-78) displayed substantial CXCR1 agonistic activity. Citrullination tended to decrease the capacity of CXCL5 to activate $G$ protein-dependent signaling, but data did not reach significance.

A second major intracellular pathway that can be stimulated by agonists in chemokine-induced signaling is mediated by $\beta$-arrestins and does not involve $G$ proteins $(30,31)$. These cytosolic phosphoproteins play a central role in desensitization and internalization of GPCRs such as chemokine receptors, and are therefore believed to be important for receptor turnover and maintaining responsiveness to renewed agonist stimulation (32-35). In addition, $\beta$-arrestins act as bridging molecules, bringing multiple components of specific signaling cascades into close proximity, thereby linking GPCRs to pathways such as mitogen-activated protein kinase (MAPK) cascades (34, 36-39). The results presented here show the different effects of CXCL5 forms, generated by posttranslational modifications, on $\beta$-arrestin recruitment through CXCR2 and internalization of the receptor. As expected from the effects we observed on $G$ protein-dependent signaling, CXCL5(9-78) and $\left[\mathrm{Cit}^{9}\right] \mathrm{CXCL5}(9-78)$ were more potent than full-length $\mathrm{CXCL5}(1-78)$ and $\left[\mathrm{Cit}^{9}\right] \mathrm{CXCL5}(1-78)$ in these alternative signaling assays. Moreover, $\mathrm{CXCL5}(1-78)$ and $\left[\mathrm{Cit}^{9}\right] \mathrm{CXCL5}(1-78)$ induced the internalization of CXCR2, but no $\beta$-arrestin recruitment was detected upon stimulation with these CXCL5 forms, supporting the notion that $\beta$-arrestin-independent mechanisms are also likely to be involved in CXCL5induced CXCR2 internalization (40). However, we need to keep in mind that different cells and time points were used for comparing the different forms of CXCL5 in ?-arrestin and internalization assays.

To explore the target cell repertoire of the CXCL5 variants in vivo, we took advantage of an i.a. model with very low basal leukocyte counts. The synthesized CXCL5 forms used in these assays were highly pure and endotoxin-free. Full-length CXCL5(1-78) and the modified forms [Cit ${ }^{9}$ CXCL5(1-78), CXCL5(978), and [ $\mathrm{Cit}^{9}{ }^{9} \mathrm{CXCL5}(9-78)$ displayed monocyte chemotactic activity in vivo. Our results demonstrated that $\mathrm{N}$-terminal modification not only enhanced the neutrophil chemotactic activity of CXCL5, but also potentiated its chemotactic effect on monocytes. The fact that CXCL5-induced monocyte recruitment in vivo was reduced upon blockage of CXCR1 and CXCR2, combined with the observation that CXCL5 did not induce the release of CCL2 or CCL3 and that CXCR1 and CXCR2 were present on murine monocytes, suggests a direct chemotactic effect of CXCL5 on monocytes through CXCR1 and/or CXCR2. 
We acknowledge that the relative contribution of the individual receptors in monocyte and neutrophil activation and migration remains undetermined.

These observations were confirmed in $\mathrm{Ca}^{2+}$ signaling and in vitro cell migration assays using monocytic THP-1 cells and CD14 ${ }^{+}$human monocytes, respectively. In all these assays, CXCL5(9-78) and $\left[\mathrm{Cit}^{9}\right] \mathrm{CXCL5}$ (9-78) were more potent than the full-length variants. Further proof that this activity on monocytes was mediated by CXCR1 and/or CXCR2 was provided with the specific CXCR2 ligand CXCL2 and with the dual-specificity CXCR1 and CXCR2 ligand CXCL8 in direct $\mathrm{Ca}^{2+}$ and in $\mathrm{Ca}^{2+}$ desensitization experiments. Based on our in vitro cell migration experiments with human monocytes, we expect a potential role for several $\mathrm{ELR}^{+} \mathrm{CXC}$ chemokines in monocyte migration, although a rather high chemokine concentration may be required for monocyte chemotaxis, as shown for CXCL2 (Fig. 4D). Our results demonstrated that the minimal effective concentration for monocyte migration may be reduced significantly upon appropriate modification of the inducing chemokine and, in particular for CXCL5, truncation strongly potentiated the monocyte-chemotactic activity of the ligand. It is known that CXCL1, CXCL2, and CXCL3 are not or only moderately potentiated by truncation, in contrast to human CXCL5 and the murine structural and functional equivalent of human CXCL5 and CXCL6 $(21,25$, 27).

To conclude, the research presented here supports the notion that the biological activity of CXCL5 is defined by posttranslational modification. Loss of its eight most $\mathrm{N}$-terminal amino acids not only enhanced the capacity of CXCL5 to induce CXCR2-dependent signaling and internalization, but also turned CXCL5 into a more potent agonist for CXCR1. Based on signaling and migration assays, we propose that the neutrophil attractant CXCL5 exhibits a monocyte chemotactic activity that depends on CXCR1 and/or CXCR2 and is strongly amplified by N-terminal truncation. Citrullination had no significant effects on CXCL5-induced $G$ protein-dependent signaling, $\beta$-arrestin recruitment and monocyte migration. Our results challenge the dogma that CXC chemokines with an ELR motif are specific for neutrophils. 


\section{Methods \& Materials}

\section{Cell lines}

Human embryonic kidney (HEK) 293 cells used in calcium mobilization experiments (vide infra) were a gift from Prof. Dr. J.-M. Wang (National Cancer Institute, Frederick, MD). These cells were stably transfected with human CXCR1 or CXCR2 and were cultured in DMEM (Lonza) complemented with $10 \%$ ( $\mathrm{v} / \mathrm{v}$ ) fetal calf serum (FCS; Gibco) and $800 \mu \mathrm{g} / \mathrm{ml}$ geneticin (Invitrogen). Human monocytic THP-1 cells (American Type Culture Collection) used in calcium mobilization assays were grown in Roswell Park Memorial Institute medium 1640 supplemented with glutamine (RPMI 1640 - GlutaMAX; Gibco) and further enriched with $10 \%(\mathrm{v} / \mathrm{v})$ FCS and $3 \%(\mathrm{w} / \mathrm{v})$ sodium bicarbonate. For cAMP and $\beta$-arrestin recruitment assays, HEK293T cells were grown in Dulbecco's Modified Eagle's Medium (DMEM) enriched with $10 \%$ (v/v) FCS, $1 \%$ (w/v) 2-[4-(2-hydroxyethyl)piperazin-1-yl]ethanesulfonic acid (HEPES; Lonza) and $1 \%(\mathrm{w} / \mathrm{v})$ penicillin-streptomycin ( $\mathrm{P} / \mathrm{S}$; Lonza). These cells were transiently transfected with CXCR2 (for CAMP assays) or with hemagglutinin (HA)-CXCR2-RLuc and Enhanced Yellow Fluorescent Protein (EYPF)-tagged $\beta$-arrestin 1 or 2 (for $\beta$-arrestin recruitment assays) as described by Vacchini et al (41). Human retinal microvascular endothelial cells (HRMVE; Cell Systems) used in induction experiments were cultured in endothelial cell growth basal medium-2 (EBM-2; Lonza).

\section{Human leukocytes}

Peripheral blood mononuclear cells (PBMCs) were isolated from 1-day-old buffy coats (Red Cross Blood Transfusion Center, Leuven, Belgium) after centrifugation $\left(10 \mathrm{~min}, 20^{\circ} \mathrm{C}, 218 \mathrm{~g}\right)$ in a density gradient (Pancoll human, $1.077 \mathrm{~g} / \mathrm{mL}$; PAN Biotech $\mathrm{GmbH}$ ). After washing with PBS twice, PBMCs were ready for use in induction experiments (vide infra). Alternatively, the isolated PBMC fraction was used for purification of CD14 positive monocytes based on magnetic cell separation using antibody-coupled beads as described (42). To assess cell purity and CXCR1/2 expression, cells were stained using the following anti-human antibodies: allophycocyanin (APC)-labeled anti-CD14, BV421-labeled antiCD66b, Alexa Fluor 700-labeled anti-CD16, phycoerythrin (PE)-labeled anti-CXCR1 and fluorescein isothiocyanate (FITC)-labeled anti-CXCR2 (all from BD Biosciences). Resuls were analyzed by flow cytometry using a BD LSRFortessa ${ }^{\mathrm{TM}}$ X-20 flow cytometer equipped with Diva software (BD Biosciences). FlowJo software (BD Biosciences) was used for downstream analysis. Peripheral blood neutrophils used in internalization assays were isolated from fresh healthy donor blood after removal of PBMCs by centrifugation ( $10 \mathrm{~min}, 20^{\circ} \mathrm{C}, 218 \mathrm{~g}$ ) in a density gradient (Pancoll) and elimination of erythrocytes by hypotonic shock ( $30 \mathrm{sec}$ ) with ultra-pure water.

\section{Chemical synthesis of CXCL5 forms}

Native human CXCL5(1-78) and the $\mathrm{NH}_{2}$-terminally modified forms [Cit ${ }^{9}$ CXCL5(1-78), $\mathrm{CXCL5}$ (9-78) and $\left[\mathrm{Cit}^{9}\right] \mathrm{CXCL5}(9-78)$ were chemically synthesized on an Activo P11 solid-phase peptide synthesizer (Activotec) based on $\mathrm{N}$-(9-fluorenyl) methoxycarbonyl (Fmoc) chemistry. Synthesized chemokines were purified to homogeneity on a Proto 300 C4 column ( $150 \times 4.6 \mathrm{~mm}$, Higgins Analytical Inc.) using reversed phase - high performance liquid chromatography. Elution was performed with an acetonitrile gradient in $0.1 \%(\mathrm{v} / \mathrm{v})$ trifluoroacetic acid (TFA) (for full-length CXCL5) or in $0.1 \%(\mathrm{v} / \mathrm{v}$ ) acetic acid (for truncated CXCL5 forms). Two percent of the effluent was used for analysis with online electrospray - 
ion trap mass spectrometry (Bruker AmaZon SL mass spectrometer; Bruker Daltonics). Purified proteins were folded into their correct conformation as described by Loos et al (43). The molecular masses and purity of correctly folded CXCL5(1-78), [Cit $\left.{ }^{9}\right]$ CXCL5(1-78), CXCL5(9-78) and [Cit $\left.{ }^{9}\right]$ CXCL5(978) were confirmed with ion trap mass spectrometry. Protein concentrations were determined with a specific sandwich ELISA and the bicinchoninic acid (BCA) protein assay (Thermo Fisher) using bovine serum albumin as reference protein. Synthesized chemokines were LPS-free as determined by the EndoZyme ${ }^{\circledR}$ II assay (Hyglos $\mathrm{GmbH}$ ) which has a detection limit of $0.005 \mathrm{EU} / \mathrm{ml}$.

\section{Intracellular calcium measurements}

CXCR1-transfected HEK293 cells and THP-1 cells were, respectively, suspended in DMEM medium enriched with $10 \%(\mathrm{v} / \mathrm{v})$ FCS and in RPMI1640 medium enriched with $10 \%(\mathrm{v} / \mathrm{v})$ FCS at a final concentration of $10^{7}$ cells per $\mathrm{ml}$. Cells were treated with $2.5 \mu \mathrm{M}$ of the fluorescent dye Fura-2AM (Invitrogen) in the presence of $0.01 \%$ (w/v) Pluronic-F127 (Sigma). Following incubation for $30 \mathrm{~min}$ at room temperature, cells were washed with indicated media. Cells were kept on ice, washed twice with $\mathrm{Ca}^{2+}$ buffer [HBSS (Invitrogen) containing $\mathrm{Ca}^{2+}$ and $\mathrm{Mg}^{2+}$ and complemented with $10 \mathrm{mM}$ HEPES (Gibco) and $0.1 \%(\mathrm{v} / \mathrm{v}) \mathrm{FCS}, \mathrm{pH} 7.4$ ] and suspended at a final concentration of $10^{6}$ cells per ml. For each measurement, $1.8 \times 10^{6}$ cells were preheated for $10 \mathrm{~min}$ at $37^{\circ} \mathrm{C}$ followed by stimulation with 3 to 600 nM CXCL5(1-78), [Cit $\left.{ }^{9}\right] \operatorname{CXCL5}(1-78), \mathrm{CXCL}^{2}(9-78)$ or [ $\left.\mathrm{Cit}^{9}\right] \mathrm{CXCL5}$ (9-78). Fluorescence measurements were performed using an LS50 B spectrofluorimeter (Perkin Elmer). Cells were treated with $50 \mu \mathrm{M}$ digitonin and $10 \mathrm{mM}$ ethylene glycol-bis( $\beta$-aminoethyl ether)- $\mathrm{N}, \mathrm{N}, \mathrm{N}^{\prime}, \mathrm{N}^{\prime}$-tetraacetic acid (EGTA; SigmaAldrich) in $20 \mathrm{mM}$ Tris (pH 8.5; Merck), to determine $R_{\max }$ and $R_{\min }$ values, respectively. WinLab32 software (Perkin Elmer) was used to calculate intracellular $\mathrm{Ca}^{2+}$ concentrations ([Ca $\left.\left.{ }^{2+}\right]_{i}\right)$ based on the Grynkiewicz equation. Fluorescence intensities of unloaded cells (not treated with Fura-2AM) were used to correct results for auto-fluorescence intrinsic to HEK293/CXCR1 cells.

\section{Internalization assay}

The potency of CXCL5 forms to induce internalization of CXCR2 on freshly purified human neutrophils was investigated using a flow cytometry-based approach, as previously described (41). Relative mean receptor expression levels (\%) were calculated as follows: $100 \times$ (MFI $_{\text {CxCL5) }}$ / ( MFI $_{\text {Buffer }}$ ), with ' $\mathrm{MFI}_{\text {CxCL5 }}$ and ' $\mathrm{MFI}_{\text {Buffer' }}$ being the mean fluorescence intensities (MFI) obtained after treatment with CXCL5 or buffer, respectively.

\section{In vitro chemotaxis assay}

To study the chemotactic potency of CXCL5 forms for CD14+ human monocytes, 48-well Boyden chamber cell migration assays were performed (44). Serial dilutions of CXCL5(1-78), [Cit $\left.{ }^{9}\right]$ CXCL5(1-78), CXCL5(9-78) and [ $\mathrm{Cit}^{9}{ }^{9} \mathrm{CXCL5}$ (9-78) were prepared in HBSS buffer enriched with $0.5 \%(\mathrm{v} / \mathrm{v})$ HSA. Monocytes were suspended in the same buffer at a final concentration of $2 \times 10^{6}$ cells per $\mathrm{ml}$. The lower compartment of the Boyden chamber was filled with chemokine dilutions $(30 \mu \mathrm{l}$ per well), and was covered with a $5-\mu \mathrm{m}$ pore size polyvinylpyrrolidone-treated polycarbonate membrane (GE Water \& Process Technologies). Cells were added to the upper part of the chamber ( $50 \mu \mathrm{l} /$ well). After incubation for 2 hours at $37^{\circ} \mathrm{C}$, membranes were fixed and stained (Hemacolor Solution I-III, Merck). The numbers of migrated cells were microscopically counted in ten separate fields for each test condition. 
Chemotactic indices were calculated through dividing the number of monocytes that migrated in response to chemokine dilution by the number of cells that migrated in response to buffer alone.

In vivo cell migration assay

The potency of $\mathrm{CXCL} 5$ forms to attract specific leukocyte subsets to the synovial cavity was determined after intra-articular (i.a.) injection as described previously (45). Briefly, 8 to 9 weeks old male C57BI/6 mice were anaesthetized with an intraperitoneal (i.p) injection of $3.75 \%(\mathrm{w} / \mathrm{v})$ ketamine plus $0.25 \%$ $(\mathrm{w} / \mathrm{v})$ xylazine in PBS, followed by injection of CXCL5(1-78) [(1 $\mu \mathrm{g}$ (experiment performed in Brazil) or $1.3 \mu \mathrm{g}$ (experiment performed in Leuven)], [Cit $\left.{ }^{9}\right] \mathrm{CXCL5}(1-78)$ [2 $\mu \mathrm{g}$ (Leuven)], CXCL5(9-78) [(0.3 $\mu \mathrm{g}$ (Brazil) or $1 \mu \mathrm{g}$ (Leuven)], [Cit ${ }^{9}$ CXCL5(9-78) [1 $\mathrm{g}$ (Brazil and Leuven)] or vehicle into the tibiofemoral articulation. Chemokine dilutions were prepared in PBS containing $0.007 \%(v / v)$ p-nitrophenyl $\beta D$ glucuronide (Sigma) in a total volume of $10 \mu$ l. Mice were sacrificed three hours after injection. Articular cavities were washed with PBS enriched with $3 \%(w / v)$ BSA. Total leukocyte numbers were determined using a Bürker or Neubauer chamber, followed by differential cell counting on slides after cytospin centrifugation. Concentrations of muCCL2 and muCCL3 in synovial fluids were measured using commercially available DuoSet ELISA's (R\&D Systems). In follow-up experiments, mice were injected subcutaneously with $30 \mathrm{mg} / \mathrm{kg}$ reparixin (Dompé Pharma) or saline 40 minutes prior to i.a. injection with a single dose (1.3 $\mu \mathrm{g})$ of CXCL5(1-78) and the same protocol was followed. Expression of CXCR1/2 on murine blood leukocytes was analyzed by flow cytometry using the following anti-mouse antibodies: Alexa Fluor 700-labeled anti-Ly6G, PE-labeled anti-CXCR1 (both from BD Biosciences), Alexa Fluor 647-labeled anti-CXCR2, FITC-labeled anti-Ly6C (both from Biolegend) and eFluor 450labeled anti-CD11b (Invitrogen). For downstream analysis with FlowJo software, neutrophils and

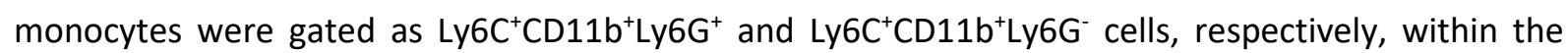
population of living cells (Zombie Aqua live-dead staining, Biolegend) that occurred as singlets only. All in vivo experiments were conducted in the animal research facilities of the University of Minas Gerais or KU Leuven after approval by the respective ethical committees.

\section{G protein signaling assay}

The AlphaScreen cAMP technology (Perkin Elmer) was used to investigate the potency of CXCL5 forms to induce a CXCR2-dependent reduction of intracellular cAMP levels (46). CXCR2-transfected HEK293T cells were suspended in stimulation buffer [1X HBSS complemented with $0.1 \%(\mathrm{w} / \mathrm{v}) \mathrm{BSA}, 0.5 \mathrm{nM} 3-$ isobutyl-1-methylxanthine (IBMX; Sigma-Aldrich) and 5 mM HEPES (Lonza)] at a final concentration of $10^{7}$ cells per $\mathrm{ml}$. Cells were seeded in a 384-well white opaque plate (Perkin Elmer) at $10^{4}$ cells per well. Subsequently, $5 \mu$ l containing 0.2 units/ $\mu$ lanti-cAMP acceptor beads was added, followed by addition of $5 \mu \mathrm{l} 10 \mu \mathrm{M}$ Forskolin and serial dilutions of CXCL5(1-78), [Cit ${ }^{9}$ ]CXCL5(1-78), CXCL5(9-78) or [Cit $\left.{ }^{9}\right]$ CXCL5(9-78). Following incubation at room temperature for $30 \mathrm{~min}, 1$ unit of streptavidin-labeled donor beads and 1 unit biotinylated CAMP diluted in a total volume of $15 \mu$ lysis buffer were added. The plate was placed in the dark for $30 \mathrm{~min}$ at room temperature. Luminescence measurements were performed on a Synergy $\mathrm{H} 4$ plate reader through a 570/100 nm filter after sample excitation with $680 / 30 \mathrm{~nm}$ filtered light. 
The Bioluminescence Resonance Energy Transfer 1 (BRET1) technique was used for examination of $\beta$ arrestin recruitment to CXCR2 upon stimulation with CXCL5 forms (46). CXCR2 and $\beta$-arrestins cotransfected HEK293T cells were harvested using $0.02 \%(\mathrm{w} / \mathrm{v})$ ethylenediaminetetraacetic acid (EDTA, Lonza) and quantified as protein content (DC Protein Assay; Bio-Rad). Cells were suspended at a final concentration of $1 \mathrm{mg} / \mathrm{ml}$ in PBS enriched with $0.1 \%(\mathrm{w} / \mathrm{v})$ glucose and seeded in an opaque white well/black frame 96 -well plate (Perkin Elmer) $(80 \mu \mathrm{g}$ of proteins per well). Following addition of $5 \mu \mathrm{M}$ coelenterazine $\mathrm{H}$ and incubation in the dark for 8 minutes at room temperature, cells were stimulated with CXCL5(1-78), [Cit $\left.{ }^{9}\right] \mathrm{CXCL5}$ (1-78), CXCL5(9-78), [Cit $\left.{ }^{9}\right] \mathrm{CXCL5}$ (9-78) or vehicle. Light emission was measured immediately at 460-500 $\mathrm{nm}$ (RLuc) and 510-550 nm (EYFP) sequentially for each well using a Synergy H4 Hybrid reader (Biotek). To calculate BRET ratios, luminescence values obtained with an EYFP filter were divided by the values obtained using an RLuc filter. The ligand effect was obtained by subtracting BRET values obtained by cells stimulated with PBS from BRET values obtained by cells stimulated with the different CXCL5 forms.

\section{Induction experiments}

Isolated human PBMCs, diluted at $2 \times 10^{6}$ cells $/ \mathrm{ml}$ in RPMI1640 medium containing $2 \%(\mathrm{v} / \mathrm{v})$ FCS and $0.01 \%(\mathrm{v} / \mathrm{v}$ ) gentamycin, were stimulated with LPS (Sigma), peptidoglycan (Sigma) or CXCL5 forms in 96-well plates. Alternatively, the same inducers were used for stimulation of human retinal microvascular endothelial (HRMVE) cells seeded in 48 -well plates in EBM- 2 medium ( $\pm 50 \%$ confluent). After $24 \mathrm{~h}$ of incubation at $37{ }^{\circ} \mathrm{C}$ and $5 \% \mathrm{CO}_{2}$, samples were centrifuged to collect supernatants. These were evaluated for the presence of huCCL2 and huCCL3 using commercially available DuoSet ELISAs (R\&D Systems) according to the manufacturer's protocol.

\section{Statistics}

No normal distribution of data was detected as evaluated by the Shapiro-Wilk test. Kruskal-Wallis tests and subsequent pairwise comparisons by Mann Whitney $\mathrm{U}$ tests or Wilcoxon tests were performed to detect significant differences. A p-value of 0.05 or less was considered significant. 


\section{References}

1. Luster, A. D. 1998. Chemokines - chemotactic cytokines that mediate inflammation. N. Engl. J. Med. 338: $436-445$.

2. Thelen, M., and J. V Stein. 2008. How chemokines invite leukocytes to dance. Nat. Immunol. 9: 953959.

3. Thelen, M. 2001. Dancing to the tune of chemokines. Nat. Immunol. 2: 129-134.

4. Strieter, R. M., S. L. Kunkel, M. D. Burdick, P. M. Lincoln, and A. Walz. 1992. The detection of a novel neutrophil-activating peptide (ENA-78) using a sensitive ELISA. Immunol. Invest. 21: 589-596.

5. Walz, A., R. Burgener, B. Car, M. Baggiolini, S. L. Kunkel, and R. M. Strieter. 1991. Structure and neutrophil-activating properties of a novel inflammatory peptide (ENA-78) with homology to interleukin 8. J. Exp. Med. 174: 1355-1362.

6. Imaizumi, T., K. H. Albertine, D. L. Jicha, T. M. McIntyre, S. M. Prescott, and G. A. Zimmerman. 1997. Human endothelial cells synthesize ENA-78: relationship to IL-8 and to signaling of PMN adhesion. Am. J. Respir. Cell Mol. Biol. 17: 181-192.

7. Schnyder-Candrian, S., and A. Walz. 1997. Neutrophil-activating protein ENA-78 and IL-8 exhibit different patterns of expression in lipopolysaccharide- and cytokine-stimulated human monocytes. $J$. Immunol. 158: 3888-3894.

8. Koch, A. E., M. V Volin, J. M. Woods, S. L. Kunkel, M. A. Connors, L. A. Harlow, D. C. Woodruff, M. D. Burdick, and R. M. Strieter. 2001. Regulation of angiogenesis by the C-X-C chemokines interleukin-8 and epithelial neutrophil activating peptide 78 in the rheumatoid joint. Arthritis Rheum. 44: 31-40.

9. Susek, K. H., M. Karvouni, E. Alici, and A. Lundqvist. 2018. The role of CXC chemokine receptors 1-4 on immune cells in the tumor microenvironment. Front. Immunol. 9: 2159.

10. Verbeke, H., K. Geboes, J. Van Damme, and S. Struyf. 2012. The role of CXC chemokines in the transition of chronic inflammation to esophageal and gastric cancer. Biochim. Biophys. Acta 1825: 117129.

11. Santoni, M., S. Bracarda, M. Nabissi, F. Massari, A. Conti, E. Bria, G. Tortora, G. Santoni, and S. Cascinu. 2014. CXC and CC chemokines as angiogenic modulators in nonhaematological tumors. Biomed Res. Int. 2014: 768758.

12. Russo, R. C., C. C. Garcia, M. M. Teixeira, and F. A. Amaral. 2014. The CXCL8/IL-8 chemokine family and its receptors in inflammatory diseases. Expert Rev. Clin. Immunol. 10: 593-619.

13. Koch, A. E., S. L. Kunkel, L. A. Harlow, D. D. Mazarakis, G. K. Haines, M. D. Burdick, R. M. Pope, A. Walz, and R. M. Strieter. 1994. Epithelial neutrophil activating peptide-78: a novel chemotactic cytokine for neutrophils in arthritis. J. Clin. Invest. 94: 1012-1018.

14. Bachelerie, F., A. Ben-Baruch, A. M. Burkhardt, C. Combadiere, J. M. Farber, G. J. Graham, R. Horuk, A. H. Sparre-Ulrich, M. Locati, A. D. Luster, A. Mantovani, K. Matsushima, P. M. Murphy, R. Nibbs, H. Nomiyama, C. A. Power, A. E. I. Proudfoot, M. M. Rosenkilde, A. Rot, S. Sozzani, M. Thelen, O. Yoshie, and A. Zlotnik. 2014. International Union of Basic and Clinical Pharmacology. [corrected]. LXXXIX. Update on the extended family of chemokine receptors and introducing a new nomenclature for atypical chemokine receptors. Pharmacol. Rev. 66: 1-79.

15. Wuyts, A., P. Proost, J. P. Lenaerts, A. Ben-Baruch, J. Van Damme, and J. M. Wang. 1998. Differential usage of the CXC chemokine receptors 1 and 2 by interleukin-8, granulocyte chemotactic protein- 2 and epithelial-cell-derived neutrophil attractant-78. Eur. J. Biochem. 255: 67-73. 
16. Ahuja, S. K., and P. M. Murphy. 1996. The CXC chemokines growth-regulated oncogene (GRO) alpha, GRObeta, GROgamma, neutrophil-activating peptide-2, and epithelial cell-derived neutrophilactivating peptide-78 are potent agonists for the type B, but not the type A, human interleukin-8 receptor. J. Biol. Chem. 271: 20545-20550.

17. Wolf, M., M. B. Delgado, S. A. Jones, B. Dewald, I. Clark-Lewis, and M. Baggiolini. 1998. Granulocyte chemotactic protein 2 acts via both IL-8 receptors, CXCR1 and CXCR2. Eur. J. Immunol. 28: 164-170.

18. Vanheule, V., M. Metzemaekers, R. Janssens, S. Struyf, and P. Proost. 2018. How post-translational modifications influence the biological activity of chemokines. Cytokine 109: 29-51.

19. Metzemaekers, M., J. Van Damme, A. Mortier, and P. Proost. 2016. Regulation of chemokine activity - a focus on the role of dipeptidyl peptidase IV/CD26. Front. Immunol. 7: 483.

20. Mortier, A., M. Gouwy, J. Van Damme, and P. Proost. 2011. Effect of posttranslational processing on the in vitro and in vivo activity of chemokines. Exp. Cell Res. 317: 642-654.

21. Mortier, A., T. Loos, M. Gouwy, I. Ronsse, J. Van Damme, and P. Proost. 2010. Posttranslational modification of the NH2-terminal region of CXCL5 by proteases or peptidylarginine Deiminases (PAD) differently affects its biological activity. J. Biol. Chem. 285: 29750-29759.

22. Van Den Steen, P. E., A. Wuyts, S. J. Husson, P. Proost, J. Van Damme, and G. Opdenakker. 2003. Gelatinase B/MMP-9 and neutrophil collagenase/MMP-8 process the chemokines human GCP2/CXCL6, ENA-78/CXCL5 and mouse GCP-2/LIX and modulate their physiological activities. Eur. J. Biochem. 270: 3739-3749.

23. Tester, A. M., J. H. Cox, A. R. Connor, A. E. Starr, R. A. Dean, X. S. Puente, C. Lopez-Otin, and C. M. Overall. 2007. LPS responsiveness and neutrophil chemotaxis in vivo require PMN MMP-8 activity. PLoS One 2: e312.

24. Wuyts, A., C. Govaerts, S. Struyf, J. P. Lenaerts, W. Put, R. Conings, P. Proost, and J. Van Damme. 1999. Isolation of the CXC chemokines ENA-78, GRO alpha and GRO gamma from tumor cells and leukocytes reveals $\mathrm{NH2}$-terminal heterogeneity. Functional comparison of different natural isoforms. Eur. J. Biochem. 260: 421-429.

25. Repnik, U., A. E. Starr, C. M. Overall, and B. Turk. 2015. Cysteine cathepsins activate ELR chemokines and inactivate non-ELR chemokines. J. Biol. Chem. 290: 13800-13811.

26. Nufer, O., M. Corbett, and A. Walz. 1999. Amino-terminal processing of chemokine ENA-78 regulates biological activity. Biochemistry 38: 636-642.

27. Wuyts, A., A. D'Haese, V. Cremers, P. Menten, J. P. Lenaerts, A. De Loof, H. Heremans, P. Proost, and J. Van Damme. 1999. NH2- and $\mathrm{COOH}$-terminal truncations of murine granulocyte chemotactic protein-2 augment the in vitro and in vivo neutrophil chemotactic potency. J. Immunol. 163: 61556163.

28. Yoshida, K., O. Korchynskyi, P. P. Tak, T. Isozaki, J. H. Ruth, P. L. Campbell, D. L. Baeten, D. M. Gerlag, M. A. Amin, and A. E. Koch. 2014. Citrullination of epithelial neutrophil-activating peptide 78/CXCL5 results in conversion from a non-monocyte-recruiting chemokine to a monocyte-recruiting chemokine. Arthritis Rheumatol. (Hoboken, N.J.) 66: 2716-2727.

29. Grynkiewicz, G., M. Poenie, and R. Y. Tsien. 1985. A new generation of Ca2+ indicators with greatly improved fluorescence properties. J. Biol. Chem. 260: 3440-3450.

30. Rajarathnam, K., M. Schnoor, R. M. Richardson, and S. Rajagopal. 2019. How do chemokines navigate neutrophils to the target site: Dissecting the structural mechanisms and signaling pathways. Cell. Signal. 54: 69-80. 
31. Steen, A., O. Larsen, S. Thiele, and M. M. Rosenkilde. 2014. Biased and G protein-independent signaling of chemokine receptors. Front. Immunol. 5: 277.

32. Barlic, J., M. H. Khandaker, E. Mahon, J. Andrews, M. E. DeVries, G. B. Mitchell, R. Rahimpour, C. M. Tan, S. S. Ferguson, and D. J. Kelvin. 1999. beta-arrestins regulate interleukin-8-induced CXCR1 internalization. J. Biol. Chem. 274: 16287-16294.

33. Rose, J. J., J. F. Foley, P. M. Murphy, and S. Venkatesan. 2004. On the mechanism and significance of ligand-induced internalization of human neutrophil chemokine receptors CXCR1 and CXCR2. J. Biol. Chem. 279: 24372-24386.

34. Su, Y., S. K. Raghuwanshi, Y. Yu, L. B. Nanney, R. M. Richardson, and A. Richmond. 2005. Altered CXCR2 signaling in beta-arrestin-2-deficient mouse models. J. Immunol. 175: 5396-5402.

35. Marchese, A. 2014. Endocytic trafficking of chemokine receptors. Curr. Opin. Cell Biol. 27: 72-77.

36. Gurevich, E. V, and V. V Gurevich. 2006. Arrestins: ubiquitous regulators of cellular signaling pathways. Genome Biol. 7: 236.

37. Ge, L., Y. Ly, M. Hollenberg, and K. DeFea. 2003. A beta-arrestin-dependent scaffold is associated with prolonged MAPK activation in pseudopodia during protease-activated receptor-2-induced chemotaxis. J. Biol. Chem. 278: 34418-34426.

38. DeWire, S. M., S. Ahn, R. J. Lefkowitz, and S. K. Shenoy. 2007. Beta-arrestins and cell signaling. Annu. Rev. Physiol. 69: 483-510.

39. Zhao, M., A. Wimmer, K. Trieu, R. G. Discipio, and I. U. Schraufstatter. 2004. Arrestin regulates MAPK activation and prevents NADPH oxidase-dependent death of cells expressing CXCR2. J. Biol. Chem. 279: 49259-49267.

40. Fan, G. H., W. Yang, J. Sai, and A. Richmond. 2001. Phosphorylation-independent association of CXCR2 with the protein phosphatase 2A core enzyme. J. Biol. Chem. 276: 16960-16968.

41. Vacchini, A., A. Mortier, P. Proost, M. Locati, M. Metzemaekers, and E. M. Borroni. 2018. Differential Effects of Posttranslational Modifications of CXCL8/Interleukin-8 on CXCR1 and CXCR2 Internalization and Signaling Properties. Int. J. Mol. Sci. 19.

42. De Buck, M., M. Gouwy, P. Proost, S. Struyf, and J. Van Damme. 2013. Identification and characterization of MIP-1alpha/CCL3 isoform 2 from bovine serum as a potent monocyte/dendritic cell chemoattractant. Biochem. Pharmacol. 85: 789-797.

43. Loos, T., A. Mortier, and P. Proost. 2009. Chapter 1. Isolation, identification, and production of posttranslationally modified chemokines. Methods Enzymol. 461: 3-29.

44. Boyden, S. 1962. The chemotactic effect of mixtures of antibody and antigen on polymorphonuclear leucocytes. J. Exp. Med. 115: 453-466.

45. Amaral, F. A., V. V Costa, L. D. Tavares, D. Sachs, F. M. Coelho, C. T. Fagundes, F. M. Soriani, T. N. Silveira, L. D. Cunha, D. S. Zamboni, V. Quesniaux, R. S. Peres, T. M. Cunha, F. Q. Cunha, B. Ryffel, D. G. Souza, and M. M. Teixeira. 2012. NLRP3 inflammasome-mediated neutrophil recruitment and hypernociception depend on leukotriene $\mathrm{B}(4)$ in a murine model of gout. Arthritis Rheum. 64: 474484.

46. Vacchini, A., M. Busnelli, B. Chini, M. Locati, and E. M. Borroni. 2016. Analysis of G protein and betaarrestin activation in chemokine receptors signaling. Methods Enzymol. 570: 421-440. 


\section{Acknowledgments}

The authors thank Lotte Vanbrabant for technical support. A.V. current affiliation is Experimental Immunology, Department of Biomedicine, University of Basel and University Hospital Basel, Basel, Switzerland.

\section{Funding}

This project has received funding from the European Union's Horizon 2020 research and innovation programme under grant agreement No 779295, the Hercules Foundation from the Flemish government (AKUL/11/31), FWO-Vlaanderen (G.0808.18N) and a C1 grant from KU Leuven $(C 16 / 17 / 10)$. A.M. was supported by a postdoctoral research grant of FWO-Vlaanderen and M.M. by a L'Oréal/UNESCO/FWO-Vlaanderen PhD scholarship.

\section{Author Contributions}

M.M., A.M., A.V., D.B., K.Y., R.J., F.M.F., S.M., N.B., N.P., F.A.A. and P.P. performed experiments. M.M., M.M.A., M.L., E.M.B., F.A.A. and P.P. designed the project. M.M. wrote the manuscript which was corrected by all authors.

\section{Competing Interests}

The authors declare that they have no competing interests.

\section{Data and Materials Availability}

All data needed to evaluate the conclusions in the paper are present in the paper or the Supplementary Materials. 


\section{Supplementary Material}

A

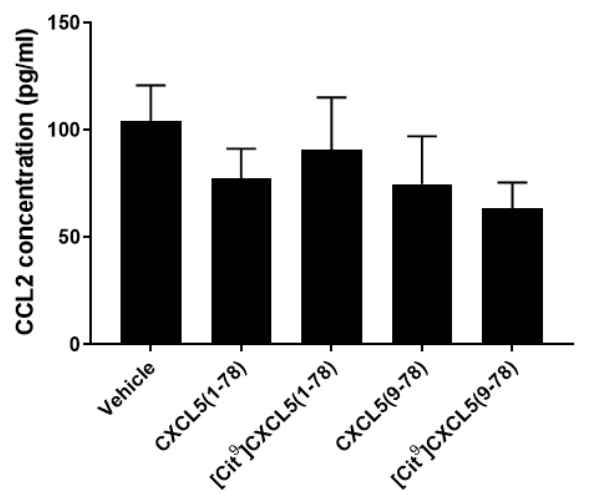

C

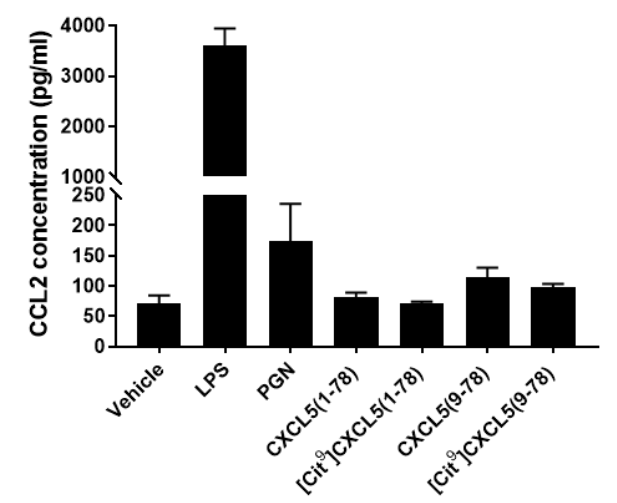

E

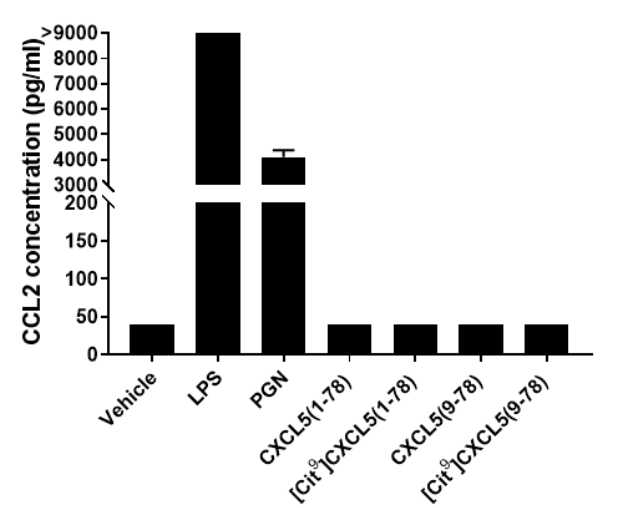

B

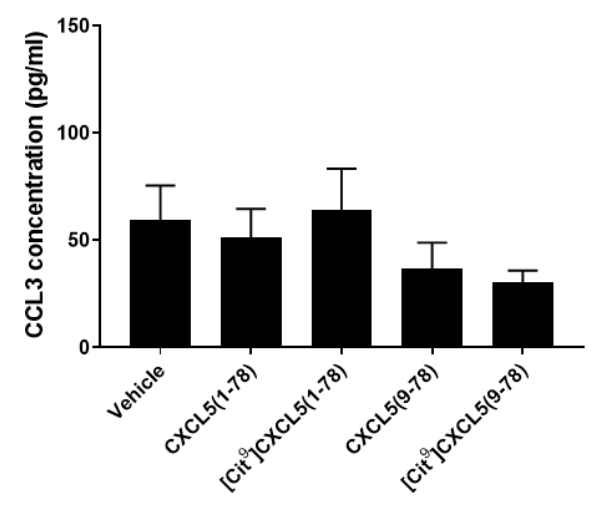

D

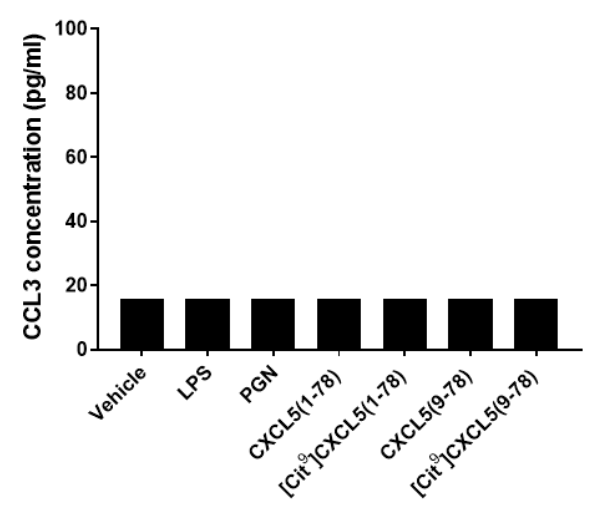

$\mathbf{F}$

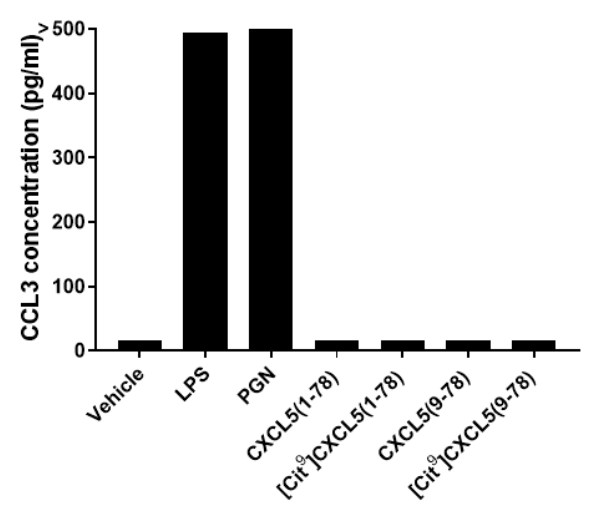

Fig. S1. CXCL5 forms fail to induce the release of monocyte chemoattractants in vitro and in vivo. (A and B) Synovial fluids from C57BL/ 6 mice were collected 3 hours after local administration of $1.3 \mu \mathrm{g} \mathrm{CXCL5(1-78),} 2 \mu \mathrm{g}$ [Cit $\left.{ }^{9}\right] \mathrm{CXCL5}(1-78), 1 \mu \mathrm{g} \mathrm{CXCL5}(9-78), 1 \mu \mathrm{g}$ [Cit $\left.{ }^{9}\right] \mathrm{CXCL5}(9-78)$, or vehicle. Mean amounts ( $\pm \mathrm{SEM}, \mathrm{n} \geq 4$ mice) of CCL2 (A) and CCL3 (B) were determined by ELISA. (C and D) The production of CCL2 (C) and CCL3 (D) by human retinal epithelial (HRMVE) cells was determined by ELISA after stimulation for 24 hours with $133 \mathrm{nM}$ CXCL5(1-

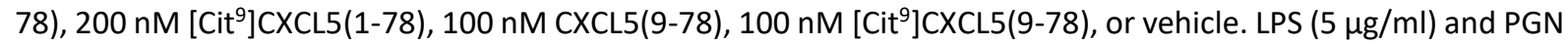
$(10 \mu \mathrm{g} / \mathrm{ml})$ were used as positive controls. Results are represented as mean \pm SEM. $\mathrm{n}=3$ independent experiments. (E and $\mathbf{F}$ ), The production of CCL2 (E) and CCL3 (F) by freshly purified human PBMCs was determined by ELISA after stimulation with $133 \mathrm{nM} \mathrm{CXCL5(1-78),} 200 \mathrm{nM}$ [Cit $\left.{ }^{9}\right] \operatorname{CXCL5}(1-78), 100 \mathrm{nM}$ CXCL5(9-78), $100 \mathrm{nM}$ [Cit ${ }^{9}$ ]CXCL5(9-78), or vehicle for 24 hours. LPS $(5 \mu \mathrm{g} / \mathrm{ml})$ and PGN $(10 \mu \mathrm{g} / \mathrm{ml})$ were used as positive controls. Results are represented as mean \pm SEM ( $n \geq 4$ independent cell preparations). All results were statistically compared by Mann-Whitney tests. 
A
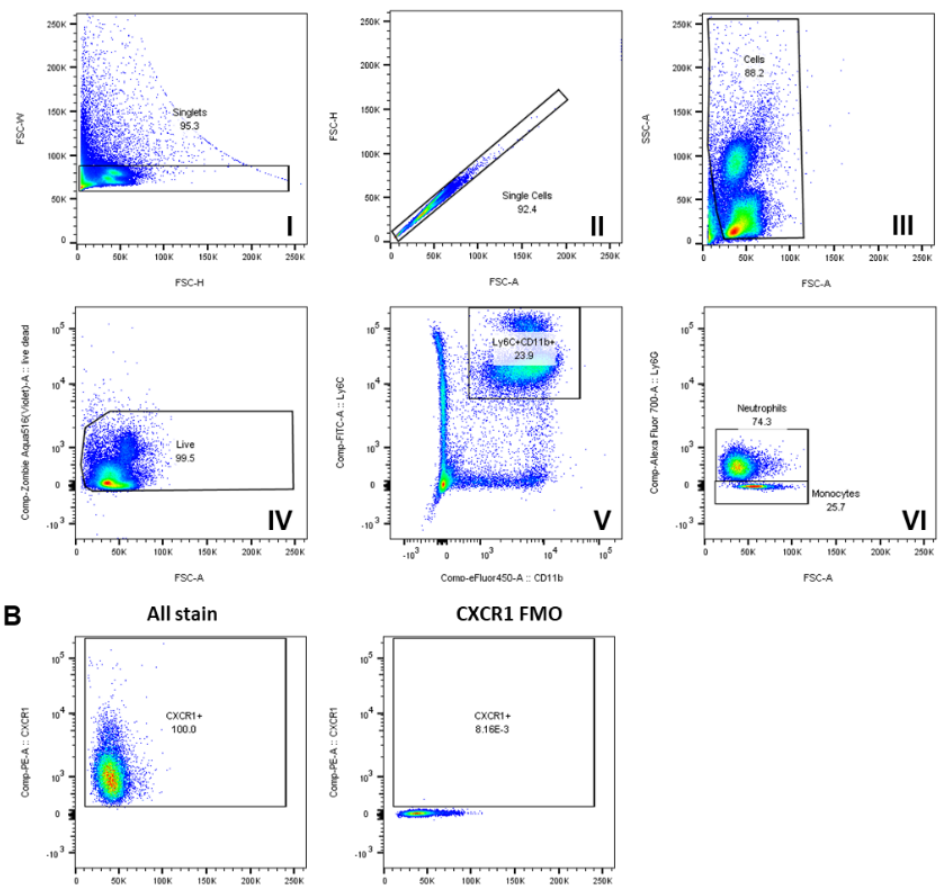

CXCR1 FMO

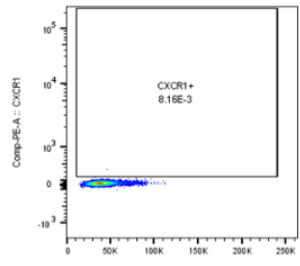

All stain

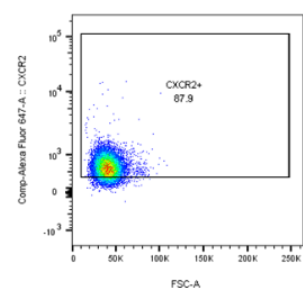

CXCR2 FMO

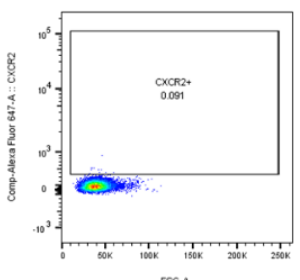

C

All stain

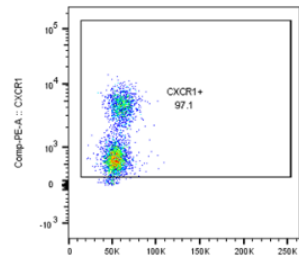

CXCR1 FMO

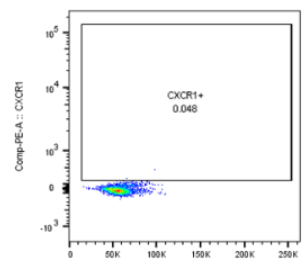

All stain
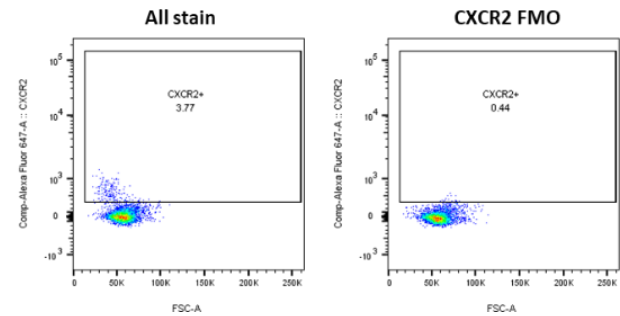

Fig. S2. Flow cytometry gating strategy. Flow cytometry was used to measure the abundance of CXCR1 and CXCR2 on murine blood leukocytes. (A) Single cells were identified by plotting forward scatter-height (FSC-H) against forward scatter-width (FSC-W) (plot I). Eventually remaining doublets were removed by plotting forward scatter-area (FSC-A) versus FSC-H (plot II). Single cells were then separated from debris by plotting FSC-A versus side scatter-area (SSC-A) (plot III). Dead cells were removed using Zombie Aqua viability dye (plot IV). Neutrophils and monocytes were selected within the population of $\mathrm{Ly}_{6 \mathrm{C}} \mathrm{C}^{+} \mathrm{CD} 11 \mathrm{~b}^{+}$leukocytes based on Ly6G expression (plot V-VI). (B) Quantification of CXCR1 and CXCR2 on murine blood neutrophils (all stain). Fluorescence minus one (FMO) controls were used to help set gates for sorting the all-stain samples. (C) Quantification of CXCR1 and CXCR2 on murine blood monocytes (all stain). FMO controls were used to help set gates for sorting the all stain samples. 